
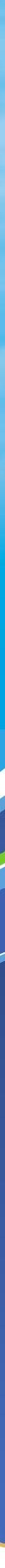


\section{Message from the Director General}

Dubai's vision is to establish a world-class food safety system that helps provide safe food to the residents and the several millions that visit the Emirate each year. We envision a system that ensures the highest standards of food safety - from the port to the plate. We would like the system to be so comprehensive and appealing that others are encouraged to use it as a model. Our vision will become a reality only when the government, food industry, service providers, educational and research organisations and the consumers collectively commit to work together and apply sound principles of food safety based on science and research.

We have begun the process by promoting a positive food safety culture among food establishments in the Emirate, by urging the management to be responsible and accountable through our proprietary Person In-Charge (PIC) program, which we introduced in 2010. The responsibility is not only with the PIC but also with other food handlers in the establishments, their owners, regulators and also the consumers. In other words, it must be stressed that food safety is a shared responsibility involving all the residents of the Emirate. Through the Food Code, we are now building on the foundations laid by the PIC and other regulatory programs, which arm them with the necessary knowledge about the systems and processes needed to ensure an effective food safety culture.

An integrated approach is necessary to ensure food safety from the place of primary production up to the point of consumption. The Food Control Department of Dubai Municipality will ensure that regulatory programs are science- and risk-based as far as possible. The Food Code is designed to assist the Person In-Charge (PICs) at food establishments to understand their obligations and to carry out operations as per the requirement.

The Food Code has been developed also to help the food industry and the law-enforcement officers understand the ways and means to meet the standards and objectives mentioned in the GCC, Federal and Local regulations. The Code also helps the Food Control Department determine compliance with these standards and enhance consistency in the interpretation and enforcement of regulations.

The key references for the Code are similar Codes issued in the United States, Canada, Australia, Ireland and Hong Kong.

The Code will be revised from time to time, and the revisions will be issued as supplements. The intention is to ensure that food safety standards move with the times and aim to encompass technologies and challenges that emerge along the way.

Eng. Hussain Nasser Lootah Director General Dubai Municipality 


\section{CONTENTS}

1 Preliminary Provisions

$\begin{array}{lll}1.1 & \text { Introduction } & 7\end{array}$

1.2 Purpose 7

$\begin{array}{lll}1.3 & \text { Application } & 7\end{array}$

1.4 Scope $\quad 8$

1.5 Guiding Principles 8

$\begin{array}{lll}1.6 & \text { Definitions } & 9\end{array}$

2 Licensing, Approvals, Construction, Design and Facilities 12

2.1 Trade License 12

2.2 Approval of Construction Plans and Specifications 12

2.3 Site and Location $\quad 12$

2.4 General Requiements for Design and Construction 13

2.5 Spatial Requirements 14

2.6 Floor, Walls and Ceilings 14

$\begin{array}{lll}2.6 .1 & \text { Floors } & 14\end{array}$

2.6.1.1 Floors in Dry Areas $\quad 14$

2.6.1.2 Floors in Wet Areas

2.6.1.3 Temporary Flooring $\quad 15$

2.6.2 Walls and Ceiling 15

$\begin{array}{ll}\text { 2.6.2.1 Walls } & 15\end{array}$

2.6.2.2 Ceiling 16

2.6.2.3 False Ceiling 16

2.7 Floor Drains 16

2.8 Stairs and Mezzanines 17

$\begin{array}{lll}2.9 & \text { Equipment and Utensils } & 17\end{array}$

$\begin{array}{ll}2.9 .1 & \text { Equipment Design and Layout }\end{array}$

$\begin{array}{ll}2.9 .2 & \text { Location of Equipment } \\ & 18\end{array}$

$\begin{array}{lll}2.9 .3 & \text { Fixed Equipment } & 18\end{array}$

$\begin{array}{ll}\text { 2.9.4 Calibration and Standardisation } & 19\end{array}$

$\begin{array}{ll}2.10 \text { Lighting } & 19\end{array}$ 
2.11 Ventilation 20

2.12 Storage Areas $\quad 20$

2.13 Water Supply $\quad 22$

2.14 Sewage and Solid Waste Disposal 22

2.15 Grease Traps 23

2.16 Plumbing System 24

2.17 Overhead Utility Lines $\quad 24$

2.18 Handwash Stations 24

2.19 Toilet Facilities and Dressing Areas 25

2.20 Cleaning Facilities $\quad 26$

2.21 Exterior Openings $\quad 26$

2.22 Temporary Food Establishments $\quad 27$

2.23 Mobile Vendors, Stalls, Catering Trucks, Dinner Cruise, Desert Events 27

2.24 Vending Machines $\quad 27$

2.24.1 Liquid Foods and Ice $\quad 27$

2.24.2 Self-Service Beverages 28

2.24.3 Beverages in Paper-Based Packaging 28

2.24.4 Vending of High Risk Foods 29

3 Control of Hazards in Food 30

3.1 Management of Food Safety 30

3.1.1 Management - Person in Charge 30

3.1.2 Roles and Responsibilities of Person in Charge 30

3.1.3 Food Safety Programmes 31

3.1.3.1 General Requirements for Food Safety Programme 31

3.1.3.2 Auditing of Food Safety Programme 31

3.1.3.3 Content of Food Safety Programme 31

3.2 Food Handling and Processing 32

3.2.1 General Requirements for Processing Food 32

3.2.2 Food Source $\quad 32$

3.2.2.1 Approved Sources 32

3.2.2.2 Unapproved Sources 33 
3.2.3 Food Receiving 33

3.2.3.1 Inspection of Incoming Food 33

3.2.3.2 Product Identification 34

3.2.3.3 Ingredient Inspection and Control 34

3.2.4 Food Additives 34

3.2.5 Handling Raw Food 35

3.2.6 Handling of Chilled and Frozen Foods 35

$\begin{array}{lll}3.2 .7 & \text { Thawing } & 35\end{array}$

3.2.8 Cooking Raw Foods of Animal Origin 36

3.2.9 Raw Ready to Eat Foods of Animal Origin 36

3.2.10 Hot Holding 36

$\begin{array}{lll}3.2 .11 & \text { Cooling after Cooking } & 37\end{array}$

3.2.12 Cooling from Room Temperature 38

3.2.13 Reheating Cooked Foods for Hot Holding 38

3.2.14 Reheating Cooked Food for Immediate Service 38

3.2.15 Use of Microwave for Cooking or Reheating 39

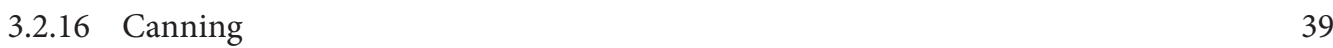

3.2.17 Use of Non-thermal Processes for Pathogen Reduction 39

3.2.18 Controlling Growth of Pathogens with Water Activity and Acid Ingredients 39

3.3 Time as a Safety Control 39

3.4 Preventing Food and Ingredient Contamination 40

3.4.1 Preventing Microbial Contamination $\quad 40$

3.4.2 Physical and Chemical Contamination 41

3.4.3 Management of Allergens 41

3.5 Packaging 42

3.5.1 General Requirements for Packaging Materials $\quad 42$

3.5.2 Protection of Food Content 43

3.5.3 Reduced Oxygen Packing 43

3.5.4 Food Containers 43

3.5.5 Reusable Packaging 44

3.5.6 Storage of Packaging Supplies 44

3.5.7 Returnables, Cleaning-for-Refilling 44 
3.6 Storage, Transportation and Distribution of Food Products

3.6.1 Food Transportation, Storage and Distribution Units 45

3.6.2 Temperature Control During Transportation and Storage 45

3.6.3 Handling and Transfer of Foods 46

$\begin{array}{lll}\text { 3.6.4 Storage Procedures } & 47\end{array}$

$\begin{array}{ll}\text { 3.6.5 Disposal of Food } & 47\end{array}$

4 Cleaning and Maintenance $\quad 48$

4.1 General Requirements Pertaining to Maintenance 48

4.2 Cleaning and Disinfection 49

4.2.1 General Requirements Pertaining to Cleaning $\quad 49$

$\begin{array}{ll}\text { 4.2.2 Cleaning Facilities } & 49\end{array}$

4.2.3 Cleaning and Disinfection Process 50

4.2.4 Cleaning Chemicals 51

4.2.5 Cleaning Tools and Equipment 52

4.2.6 Cleaning and Disinfection Programme 52

4.3 Pest Control 53

4.4 Prevention and Control of Pest Infestation 53

4.5 Use of Chemicals and Toxic Substances 56

5 Personal Hygiene $\quad 57$

5.1 Personal Health and Illnesses 57

5.2 Injuries 57

5.3 Personal Hygiene Practices 58

5.4 Personal Habits $\quad 59$

5.5 Visitors $\quad 59$

6 Training of Food Handlers $\quad 60$

6.1 Role of the Person in Charge $\quad 60$

$\begin{array}{ll}6.2 & \text { Training Programme }\end{array}$

6.3 Continuing Educational Training $\quad 60$

7 Provisions Applicable to Sale, Import and Export of Food 62

7.1 Registration and Approvals $\quad 62$ 
7.3 Food Inspection and Document Verification

8 Miscellaneous

8.1 Food Labelling $\quad 64$

\begin{tabular}{ll}
8.2 & Product Shelf Life \\
\hline
\end{tabular}

8.3 Product Menu in Food Service Establishments 66

8.4 Filtration and Disinfection Facilities for Fish Tank Water 66

$\begin{array}{lll}8.5 & \text { Single Use items } & 66\end{array}$

$\begin{array}{ll}\text { 8.6 Prohibition of Animals } & 67\end{array}$

$\begin{array}{lll}\text { 8.7 Procedures for Handling Non-Halal Food } & 67\end{array}$

8.7.1 Requirements for Imports, Purchase and Sale of Non-Halal Food 67

8.7.2 Requirements for Storage of Non-Halal Food 67

8.7.3 Requirements for Preparation of Non-Halal Food $\quad 68$

8.7.4 Serving Non Halal Foods in Restaurants 68

$\begin{array}{lll}\text { 8.7.5 Sale of Pork Products } & 69\end{array}$

8.8 Product Traceability and Recall $\quad 69$

$\begin{array}{lll}8.9 & \text { Customer Complaint Handling } & 70\end{array}$

$\begin{array}{ll}8.10 \text { Power Outage } & 70\end{array}$

$\begin{array}{ll}8.11 \text { Use of Wood in Food Premises } & 70\end{array}$

$\begin{array}{ll}8.12 \text { Use of Linen and Other Accessories } & 71\end{array}$

$\begin{array}{lr}\text { Annex } & 73\end{array}$ 


\section{Preliminary Provisions}

\subsection{Introduction}

Foodborne illness can be very serious and even life-threatening to some consumers, especially children, pregnant women, elderly, and those with impaired immune systems or allergies. Effective control of foodborne illness is vital, not only to avoid adverse effects on human health, but also to safeguard the food industry. The potential business repercussions of foodborne illness are many, including loss of earnings; unemployment and litigation; damage to trade and tourism through negative publicity; lower staff morale; and professional embarrassment. The challenge is to continually reduce the risks and achieve excellence in food safety, while supporting the ability of the food industry to adapt to new technology and survive in a competitive environment.

\subsection{Purpose}

The purpose of this Code is to provide a set of model requirements to help food establishments achieve a higher degree of compliance with the food regulations, and attain a higher standard of food safety through adoption of good practices. It also provides law enforcement officers of the Food Control Department and persons engaged in food business a common set of comprehensive advice and guidance on the application of the relevant regulations and recommended ways for compliance, with a view to improving consistency in the interpretation and application of the food regulations by all stakeholders.

The ultimate objective of the Code is to provide high level of protection to human life and health and to protect the interests of the consumers by safeguarding them from fraudulent or deceptive practices, adulteration and any other practices that may cause illness or injury to the consumer.

\subsection{Application}

a. The Code is an interpretative guideline that explains how to meet the objectives identified in the Administrative and Local Orders passed by the Government of Dubai. It is not intended to be used as a rigid and inflexible document.

b. The term "shall" or "must" is used throughout this document to indicate those provisions which the food establishments have to comply with and are an absolute requirement.

The term "should" is used to indicate those provisions which the food establishments have to comply with. However, deviations from such provisions are allowed under exceptional circumstances when there is a valid reason to ignore or to seek alternative measures without compromising the food safety objective.

The term "shall not" is used to indicate that the provisions that are absolutely prohibited.

The term "should not" is used to indicate those provisions that are prohibited. However, deviations from such provisions are allowed under exceptional circumstances when there is a valid reason to ignore or to seek alternative measures without compromising the food safety objective.

c. This document provides an extensive information base to assist in the safe operation of food establishments. As new technology becomes available, operational procedures and equipment standards in a food establishment may vary from that described in this Code. 
d. Unless specifically mentioned elsewhere in this requirement, the provisions of this requirement apply to food products -

i Manufactured, sold or prepared for sale in the Emirate of Dubai;

ii Imported directly or brought into the Dubai from other Emirates;

iii Exported to other countries.

Note: Processes, materials and methods other than those specified in the Code may be used by food business operators, if the operators can provide sound, scientific evidence to the Food Control Department that clearly demonstrate that those processes, materials and methods comply with the regulatory objectives.

\subsection{Scope}

The requirements apply to every food establishment which imports, sells, offers for sale or distributes free of charge, packages, prepares, displays, serves, manufactures, processes, or distributes food. The Code has, as its primary focus, a broad range of food establishments that include, but are not limited to, the following:

i restaurants, hotels, cafeterias and cafés;

ii food service operations in institutions, including hospitals and schools;

iii bakeries;

iv butcheries;

v grocery store, supermarkets and departmental stores;

vi food catering units, suppliers to cruise ships, events (desert camps), canteens;

vii food factories and warehouses;

viii kiosks, temporary or permanent food events, and mobile vending operations;

ix food packing material manufacturers and suppliers.

\subsection{Guiding Principles}

a. The primary objective of the Code is to ensure the safety of foods that would offer high level of public health protection. In addition, there are a number of other expected outcomes:

i better knowledge of safe food handling practices by all stakeholders;

ii improved consistency in the interpretation and application of food industry regulations by all stakeholders;

iii establishment of minimum health and food safety practices;

iv better communication among all sectors of the industry and government concerning critical requirements in food safety, and a greater commitment to finding cooperative approaches to handling risks; and

$\mathrm{v}$ improved information concerning best practices to compliment industry-driven inspection, auditing and educational programmes. 


\subsection{Definitions}

Audit: A systematic, independent and documented process for obtaining audit evidence and evaluating it objectively to determine the extent to which the audit criteria are fulfilled.

Auditor: The person with necessary competency in food safety approved by Dubai Municipality to conduct an audit.

Authorised Officer/Person: An Authorised person from the Food Control Department who can conduct inspections or investigations in food establishments.

Cleaning: The process of removing soil, food residues, dirt, grease and other objectionable matter.

Codex: Codex Alimentarius Commission (CAC), a United Nations Organisation that supports FAO and WHO by developing food standards, guidelines and Codes of practice.

Concerned Department: Departments of Dubai Municipality authorised to ensure compliance with relevant regulations.

Contamination: The introduction or occurrence of a contaminant in food or the food environment.

Control Measure: An action or activity that can be used to prevent, eliminate, or reduce a hazard to an acceptable level.

Corrective action: An Action to be taken when the results of monitoring at the CCP indicate a loss of control.

Disinfection: The reduction of microbial load, by means of hygienic chemical or physical agents, to a level that will not compromise food stability or lead to harmful contamination of food.

Equivalent: In respect to different systems, capable of meeting the same objectives.

Food: Any substance or product intended to be or reasonably expected to be ingested by people. This includes beverages and drinks (except alcohol), chewing gum and any substance including water.

Food Control Department or Department: Food Control Department of Dubai Municipality.

Food Establishment/Food Business: Any place where food is manufactured, prepared, traded or sold directly or indirectly to the consumer. The term includes any such place regardless of whether consumption is on or off the premises. The term includes but is not limited to trading companies, manufacturing companies, hotels, restaurants, cafés, cafeterias, caterers in hospitals, private clubs, caterers or cafeterias in labour camps, public and private educational bodies, groceries, supermarkets, meat and fish shops, bakeries, mobile vendors, temporary kitchens and snack houses in petrol stations. Unless specified otherwise, the term refers to establishments located in the Emirate of Dubai.

Food Establishment/Food Business Operators: A 'food business operator' means the person who is actively engaged in running the food establishment and is responsible for ensuring that the legal requirements are met.

Food Handler: Any person handling food directly or indirectly in a food establishment, whether packaged or unpackaged food, food equipment and utensils or food contact surfaces.

Food Hygiene: All conditions and measures necessary to control hazards and ensure the safety and suitability of food at all stages of the food chain.

Food Safety Course/Qualification: A course/qualification approved by the Department in accordance with the provisions of this Code.

Food Safety Programme: A food safety management system based on the principles of HACCP. 
Food Transportation Vehicle: Any mode of transport, designated for food, whether self-propelled or not and whether used on land, sea or in the air.

Food Service Establishments: Food establishments such as catering, restaurants, cafeteria, cafe and supermarkets etc. that sell portions of foods directly to the consumers for immediate consumption either on-site or off-site. The definition excludes business activities such as manufacturing, processing, trading, grocery stores etc.

Good Hygiene Practices: All practices regarding the conditions and measures necessary to ensure the safety and suitability of food at all stages of the food chain.

HACCP (Hazard Analysis and Critical Control Point): A preventive system of food safety management that identifies, evaluates, and controls hazards which are significant to food safety based on product design, hazard analysis and process control.

HACCP plan: A document prepared in accordance with the principles of HACCP to ensure control of hazards that are significant for food safety in the segment of the food chain under consideration.

Hazard: A biological, chemical or physical agent in, or condition of, food with the potential to cause an adverse effect.

Hazard analysis: The process of collecting and evaluating information on hazards and conditions leading to their presence to decide which are significant for food safety and therefore should be addressed in the HACCP plan.

High-Risk Foods: High-risk foods are foods which will support the growth of food poisoning bacteria or the formation of toxins AND which are ready to eat.

Foods such as:

- ready to eat foods such as sandwiches, pizzas, hot meals;

- cooked products containing meat, fish, cheese etc.;

- cooked products that are reheated and served - pies, ready made meals, etc.;

- $\quad$ smoked or cured meats and fish;

- $\quad$ raw ready to eat foods -e.g. Oysters, Kebneyah, Sushi;

- dairy based desserts;

- $\quad$ ripened soft or moulded cheese - e.g. Brie, Danish Blue, etc.;

- prepared vegetable salads including those containing fruit;

- foods labelled/described as needing to be kept at a specific temperature;

- frozen food such as ice cream.

Packaging: Any operation consisting of placing the food in containers (i.e. primary packaging) or placing the food containers in further packaging material (i.e. secondary packaging).

Raw Animal Foods: Raw foods of animal origin such as meat, poultry products, fish, shellfish etc. that are likely to be contaminated with pathogenic or spoilage microorganisms. They are usually stored chilled or frozen to minimise spoilage. 
Person in Charge: A person directly responsible for the food related operations in the food establishment and has direct authority, control or supervision over employees who engage in the storage, preparation, display, or service of foods.

Pests: The term pest in this document refers to any undesirable animal or insects including, but not limited to, birds, rodents, flies, larvae etc. that live in or on our food and are objectionable or a nuisance.

Potable Water: Drinking water that is pure and healthy at the point of usage, and meets the requirements of Gulf Standards.

Primary Product: Products of primary production including products of the soil, farming and fishing.

Processing: Action(s) that substantially alters the initial product, including heating, smoking, curing, maturing, drying, marinating, extraction, extrusion or a combination of those processes.

Raw Food: Food that is neither cooked nor heat processed.

Ready-to-Eat Foods: Any food for consumption without further treatment or processing. Examples of ready-to-eat food items may include: sliced cooked meats, cooked meat products and preparations, cooked/roast chickens, sandwiches and filled rolls, dairy products such as milk and cheese, fruits, prewashed/topped and tailed vegetables, prepared vegetable salads, whole salad items such as tomatoes or cucumbers, open and canned ready-to-eat fish and fish products such as salmon, tuna or sardines, shellfish, preserves and jams, condiments, bread, confectionery and biscuits.

Recall: A recall is an action taken to remove from distribution, sale and consumption, food which may pose a health risk to consumers.

Shelf- life: The period during which a food product maintains its microbiological safety and suitability at a specified storage temperature and where appropriate, specified storage and handling conditions.

Traceability: The ability to track any food, feed, food-producing animal or substance that will be used for consumption, through all stages of production, processing and distribution.

Validation: Obtaining evidence that a control measure or combination of control measures, if properly implemented, is capable of controlling the hazard to a specified outcome.

Verification: The application of methods, procedures, tests and other evaluations, in addition to monitoring, to determine whether a control measure is or has been operating as intended. 


\section{Licensing, Approvals, Construction, Design and Facilities}

\subsection{Trade License}

a. All food establishments in Dubai must have a valid trade licence from the concerned government authorities in Dubai before the start of operation.

b. The operator of the food establishment must choose the appropriate business activity at the time of obtaining the license.

c. The business activity on the trade license of food establishments shall be related to food, and the license must clearly state the exact activity the establishment is involved in.

d. Food establishments shall not carry out any other activity other than the business activity (or activities) listed in the trade license.

\subsection{Approval of Construction Plans and Specifications}

a. Proposed layouts for new construction, or renovations to an existing food establishment, shall be reviewed for compliance with the existing regulations and approved by the Food Control Department prior to the construction, renovation or re-construction.

b. In existing facilities, major alterations that affect the main layout or the process flow shall not be carried out without prior approval from the Food Control Department. Alteration, addition or deletion, which results in change of the approved layout, such as change in area of the establishment or the food rooms, addition, deletion or repositioning of equipment of a substantial and permanent nature, drainage works, passageways and open spaces, means of exit, entry and internal communication, windows and ventilating systems in production area etc., should not be carried out without the prior approval of the Food Control Department.

c. Plans for minor alterations that do not involve a change in the main layout and the flow of work such as the installation of shelves in a store room do not require prior approval.

d. A licensee has to submit the layout of the establishment for approval to the Food Control Department prior to construction. Particulars to be indicated on a layout plan include but are not limited to:

i area and space allocated to food handling and cooking, cleaning, food storage and seating;

ii sanitary fitments, open spaces, restrooms, storage areas;

iii all windows and mechanical ventilating systems;

iv layout of equipment;

$\mathrm{v}$ all means of exit and entry;

vi facilities to carry out pot and dish washing, handwashing etc.

\subsection{Site and Location}

a. Sites for food establishments should be chosen such that they are free from conditions that might interfere with their sanitary operation. Food establishments should be set far enough apart from waste disposal facilities and incompatible processing facilities so there is no risk of contamination. 
b. Generally a minimum distance of 30 metres is recommended from potential sources of contamination. However, a greater or lesser distance could be accepted depending on specific site conditions.

c. Streets, lanes and other public places or the common part of the building, which are within a minimum of 10 metres around the food establishment, should be kept clean and free of litter, garbage or waste that can attract pests.

Rationale:

Poorly maintained or unhygienic surroundings and facilities can lead to contamination of food. Conditions which might lead to contamination include excessive dust, foul odours, smoke, pest infestations, airborne microbial and chemical contaminants, and other similar conditions. Food establishments should be protected from such conditions that would expose the food to contaminants.

\subsection{General Requirements for Design and Construction}

a. The design and construction of food establishment should:

i be appropriate for the activities for which the establishment is used;

ii provide adequate space for the activities to be conducted in the establishment and be suitable for the fixtures, fittings and equipment used for those activities;

iii permit the food premises to be effectively cleaned and disinfected.

b. The design and construction should:

i help exclude dirt, dust, fumes, smoke and other contaminants;

ii not permit the entry of pests;

iii not provide harbourage for pests; and

iv provide a safe environment for workers and where applicable for customers.

c. The layout of food establishment should be designed in such a manner that:

i food flow is in one direction;

(i.e. from receiving $\rightarrow$ to storage $\rightarrow$ to preparation $\rightarrow$ to cooking $\rightarrow$ to packaging /serving despatch)

ii adequate spaces are provided for food preparation, cooking and cooling, food storage, storage of equipment / utensils, installation of sanitary fitments, and cleaning facilities;

iii food or clean eating utensils are not conveyed through an open space or open yard that would expose food to contaminants.

d. Incompatible areas or processes, particularly toilets, clean-up and chemical storage areas, should be separated from food preparation/processing areas. 
Rationale:

A properly designed and operated food establishment will minimise the likelihood of food contamination. At the same time, unnecessary movement of food and personnel within the premises increases the likelihood of contamination, and hence should be controlled as much as possible. Well designed layout is a pre-requisite for effective implementation of any food safety programme.

\subsection{Spatial Requirements}

a. The space available in a food establishment should be suitable for the business activity, and sufficient to carry out the operations as per the relevant provisions of this Code.

b. Requirements specific to the type of food establishments are provided as a separate guideline. Total area of food establishments should not be less than the minimum requirements stipulated in the layout approval guideline for food establishments.

c. Food and food handling activities should only be carried out within the area as delineated in the approved layout plan. No food related activity, such as washing of equipment and utensils, food preparation and cooking of food, and storage of utensils, equipment and food, should extend to any place beyond the approved area.

Rationale:

Adequate space for food preparation is essential to ensure safe food preparation and shall support the type of operation and the number of customers to be served. For example, too small a kitchen for a restaurant may cause congestion and unhygienic food operation that increases the risk of food contamination. The general rule for food service establishments is that, establishments with larger gross floor area should provide more space for food preparation. The type of food, number of meals produced and the number of people working at the same time should also be considered while deciding the spatial requirements for food service establishments.

\subsection{Floor, Walls and Ceilings}

The requirements in this section apply to the floors, walls and ceilings of all areas used for food handling and associated activities such as storage and packaging.

\subsubsection{Floors}

Floors should be designed and constructed in a way that is appropriate for the activities conducted in the food establishment.

\subsubsection{Floors in Dry Areas}

a. In dry areas the floor should be durable, impervious, easily cleanable, and non-slip.

b. The floor to wall joints should be coved. 


\subsubsection{Floors in Wet Areas}

a. In areas where the floor could be wet (such as food preparation or processing areas, walk-in coolers, washrooms), and areas subject to flushing or spray cleaning, the floor should be:

i light coloured;

ii durable, easily cleanable and non-slip;

iii constructed of a impervious material that is able to withstand regular wet washing, such as tile or resin;

iv coved at the wall to floor joints, and sealed;

$\mathrm{v}$ designed to prevent the pooling of liquids; and

vi sufficiently sloped for liquids to drain to adequately sized and constructed floor drains (See Section 2.7 below). Generally, a minimum slope of $2 \%$ is recommended.

b. If used, clean rubber or plastic mats, excluding carpet or other similar floor coverings, should be designed for easy removal, cleaning and, if necessary disinfection.

c. Absorbent material (e.g. cardboard, newspaper, sponge, unsuitable rubber mats) should not be used as floor material.

\subsubsection{Temporary Flooring}

Requirements as listed in 2.6.1.1 and 2.6.1.2 should be taken into account while constructing temporary floors.

Rationale:

Properly constructed floors facilitate cleaning and disinfection. Impervious materials do not absorb water or organic matter, and sloping helps avoid pooling of liquids which can lead to unhygienic conditions.

\subsubsection{Walls and Ceiling}

\subsubsection{Walls}

a. Walls should be designed and constructed in such a way that they can be kept clean.

b. In wet areas, walls should be constructed of an impervious material that is able to withstand regular washing.

c. In areas where open food is handled, internal surfaces of walls and partitions should be surfaced with smooth, preferably light coloured, durable, non-absorbent and easily cleanable materials (e.g. tiles or stainless steel) to a height of not less than 2 Metres. The rest may be painted in a light-colour. Junctions between walls, partitions and floors should be coved. 


\subsubsection{Ceiling}

a. Ceiling should be of continuous construction so that there are no empty spaces or wide joints. Although ceilings are less likely to require frequent cleaning, the surfaces should allow ease of cleaning.

b. Ceiling in kitchens and food rooms should be of light colour and fire proof.

\subsubsection{False Ceiling}

a. False ceiling if used in food handling areas should have smooth, easily cleanable and impervious surfaces.

b. Access openings to the space above false ceiling should be provided to facilitate cleaning and for detection of signs of pest infestation.

c. Ceiling or the interior of the roof and overhead fixtures are to be constructed in a way that prevents accumulation of dirt. There should be adequate measures in place to reduce condensation and subsequent growth of undesirable mould.

Rationale:

Light coloured walls and ceilings enable easy detection of dirt for prompt removal. Durable, impervious and easily cleanable surfaces facilitate cleaning work. However, note that the emphasis should be on cleanliness which is the primary objective of this provision.

The space between false ceiling and the original ceiling can get dirty and harbour pests. Periodic checks and cleaning are necessary to maintain a healthy and hygienic work environment.

\subsection{Floor Drains}

a. Floor drains must be designed to:

i effectively remove waste water;

ii be easily accessible for cleaning, and equipped with removable and cleanable covers.

b. Drain lines must be sloped, properly trapped, vented and connected to a proper drainage system.

c. The drainage system must be constructed such that there is no cross-connection between the drains or drain lines, and:

i the water supply; or

ii the food product lines or equipment.

\section{Rationale:}

The accumulation of waste water on the floor and drain of a food establishment can lead to insanitary conditions. Properly designed drains and drain lines can eliminate the accumulation of waste water and prevent entry and growth of pests. 


\subsection{Stairs and Mezzanines}

a. Stairways should be:

i located so as to minimise the risk of food contamination; and

ii constructed of materials that are impervious and easily cleanable.

b. Mezzanines should:

i not be located over food preparation areas where splashing or dripping could pose a contamination risk;

ii be constructed of solid masonry or metal construction; and

iii be equipped, where appropriate, with raised edges of a height sufficient to prevent contaminants from falling onto surfaces below.

Rationale:

Stairs and mezzanines, whether over work areas or exposed food or near these areas can act as a source of contamination. Proper design and construction can prevent this.

\subsection{Equipment and Utensils}

Food establishments shall use only safe and suitable equipment and utensils at all times. Equipment and utensils should be designed and constructed to be durable and to retain their characteristic qualities under normal use and conditions.

\subsubsection{Equipment Design and Layout}

a. Equipment and utensils should be made of safe and suitable material that will not affect the quality and safety of food.

b. Materials used for making the equipment and utensil should be resistant to denting, pitting, chipping and cracking. Food contact surfaces should be smooth so as to enable them to be kept clean, and where necessary disinfected.

c. Materials used in the construction and repair of equipment and utensils are to be non-toxic, not affected by foods, cleaning compounds, non-absorbent and durable under normal use. They are not to impart odour, colour or taste nor contribute to the contamination of food, and are to maintain their original properties under repeated use. Painted food-contact surfaces are prohibited.

d. Equipment and utensils are to be free from difficult-to-clean internal corners and crevices. Foodcontact surfaces are to be readily accessible for cleaning. Where necessary, equipment should be movable or capable of being disassembled to allow for maintenance, cleaning and disinfection.

e. Hard maple or other equivalent non-absorbent material meeting the criteria stated in this Code may be used for cutting blocks and cutting boards, baker's tables and work surfaces. Food contact surface should be smooth and maintained clean.

f. Canvas, cloth and other porous material, other than for single-service use, are prohibited as a foodcontact surface. 
g. Equipment should function in accordance with its intended use.

h. Equipment used to cook, heat treat, cool, store or freeze food should be designed to achieve the required temperatures as rapidly as necessary to ensure food safety.

i. Equipment containing bearings and gears requiring lubricants is to be designed and constructed so that the lubricant cannot leak, drip or be forced into the food or onto food-contact surfaces. Food-grade lubricants are to be used on or within food-contact surfaces.

\subsubsection{Location of Equipment}

a. Equipment used in a food establishment should be suitably located or positioned so that it:

i is not exposed to any sources of contamination;

ii can be maintained, cleaned and disinfected;

iii can be inspected easily;

iv may be properly vented when required; and

$\mathrm{v}$ is installed in such a manner as to allow adequate cleaning of the equipment and the surrounding area.

b. Equipment and utensils used in processing, handling and storage of foods (including single-service and single-use articles) shall not be located in staff locker rooms, toilet rooms, garbage storage rooms, mechanical rooms, under sewer or water lines not shielded to intercept leakage/condensate, under open stairwells, or any area where the equipment may become contaminated.

c. Unobstructed aisles, walkways and working spaces are to be provided of sufficient width to permit employees to perform their duties readily without contamination of food or food-contact surfaces by clothing or personal contact.

\section{Rationale:}

Equipment used in a food establishment shall be kept in a clean and sanitary condition to minimise the risk of contamination of food by equipment surfaces. Therefore, when considering the location of equipment, several factors should be taken into account, including ease of cleaning, the intended use of equipment, and the methods for prevention of contamination of the equipment. Special care should be taken in the placement of food equipment which will be used to process, handle or store food. Such equipment shall not be located in areas where it may become contaminated, since the surfaces of the equipment will be coming in direct contact with food.

\subsubsection{Fixed Equipment}

a. Equipment that is fixed (i.e., not easily moved) should be either:

i sealed to adjoining walls, floors and equipment; or

ii spaced in such a manner to comfortablly allow cleaning under and around the equipment.

b. Equipment that is intended to be "Clean in Place (CIP)" should be designed and constructed so that:

i cleaning and disinfection solutions circulate through a fixed system and contact all interior food contact surfaces; 
ii the system is self-draining or capable of being completely drained of cleaning and disinfectant solutions;

iii there are inspection access points to ensure all interior food contact surfaces throughout the fixed system are being effectively cleaned.

\subsubsection{Calibration and Standardisation}

Equipment or instruments used for measuring or monitoring products or processes that could have an impact on product safety or legality should be calibrated or standardised to a standard recognised by the Food Control Department. The calibration or standardisation should be done internally or externally at a pre-determined frequency necessary to ensure proper functioning of the equipment.

\section{$2.10 \quad$ Lighting}

a. Lighting and lighting fixtures should be designed to prevent accumulation of dirt and be easily cleanable.

b. Food establishment should be supplied with sufficient natural or artificial light to ensure the safe and sanitary production of food, and facilitate cleaning of the premises. Unless otherwise specified, the minimum lighting intensities should be:

i $110 \operatorname{lux}$ (at a distance of $89 \mathrm{~cm}$ ( $3 \mathrm{ft}$.) above the floor) in walk-in coolers, dry food storage areas, and in all other areas and rooms during periods of cleaning;

ii $220 \mathrm{lux}$ (at a distance of $89 \mathrm{~cm}$ (3 ft.) above the floor) in areas where fresh produce or packaged foods are sold or offered for consumption; areas used for hand washing, ware-washing, and equipment and utensil storage; and in toilet rooms; and

iii 500 lux at the surface where a food handler is working with unpackaged high risk foods or with food utensils and equipment such as knives, slicers, grinders or saws where employee/worker safety is a factor.

c. Except as otherwise specified, lighting fixtures should be shatter proof or be shielded with shatterproof coverings in areas where they are exposed to food, equipment, utensils, linens or unwrapped packing materials. Shielded lighting is not necessary in areas used only for storing food in unopened packages or where the food cannot be affected by broken glass falling onto it.

Rationale:

Adequate lighting promotes cleanliness by facilitating the identification of unclean areas. Shielding of lights to prevent the contamination of food from glass fragments in the event of breakage is an essential public health protection measure. In addition to that, risk of breakage also occurs when diffusers are removed for cleaning or changing tubes. 


\subsection{Ventilation}

a. Food establishment should be provided with adequate mechanical or mixed mode ventilation to ensure good indoor air quality.

b. The design and installation of mechanical ventilation systems should be based on the requirements provided by the Public Health and Safety Department of Dubai Municipality. Where necessary, food establishments should comply with the following Technical Guidelines relevant to food establishments published by the concerned department/s such as:

i Indoor Air Quality Requirements within Green Building Regulations and Specifications; ii Manual for Regulation of Smoking in Public Places.

c. Ventilation systems should be designed and installed such that:

i they are sufficient in number and capacity to prevent grease or condensation from collecting on the walls and ceiling;

ii the filters or other grease extracting equipment are easily removable for cleaning and replacement if not designed to be cleaned in place;

iii the exhaust ventilation hood systems include components such as hoods, fans, guards, and ducting which will prevent grease or condensation from draining or dripping onto food, food contact equipment or surfaces, utensils and linens, or single-service and single-use articles; and

iv they are equipped with make-up air systems, installed in accordance with the requirements of the Public Health and Safety Department of Dubai Municipality.

d. Mechanical ventilation systems should be installed in such a manner that airflow is directed from the clean area to the contaminated area.

e. Ventilation systems should be cleaned in accordance with the requirements stipulated by the concerned department of Dubai Municipality.

Note: The documents listed in Section 2.11 (b) are available on the website www.dm.gov.ae

Rationale:

The air supplied to the food premises shall be of sufficient quality so as not to contaminate the equipment or the food. Unclean air, excessive dust, odours, or build-up of condensation or grease are all potential sources of food contamination. Build up of grease/fat in equipment such as range hoods also pose a fire hazard.

\subsection{Storage Areas}

a. Food establishments require adequate storage facilities for all items required for operation, including food, food ingredients, equipment, and non-food materials such as utensils, linens, single-service and single-use articles, packaging, and chemical agents. During storage, food items shall be protected from contamination such as water leakage, pest infestation or any other insanitary condition. 
b. The following criteria should be applied to all storage areas:

i adequate shelving should be supplied in order that all materials may be stored off the floor. All food and food items and equipment should be stored at a minimum of $15 \mathrm{~cm}(6 \mathrm{in}$.) off the floor on racks, shelves or pallets. Shelving which is not sealed to the floor should have a clear vertical space of at least $20 \mathrm{~cm}$ between the bottom shelf and the floor to facilitate cleaning. Wide shelving units should be at least $20 \mathrm{~cm}$ or more away from the walls to allow for access for cleaning, and permit easier visual inspection;

ii shelves should be constructed of materials which are durable and easily cleaned.

c. The facilities used for the storage of food, food ingredients, equipment and packaging should be designed and constructed so that they:

i are cleanable;

ii are located in a clean and dry location;

iii restrict pest access and harbourage;

iv provide an environment which minimises the deterioration of stored materials; and

$\mathrm{v}$ protect food from contamination during storage.

d. The facilities used for the storage of food, food ingredients, equipment and packaging materials should not be located:

i in areas used for the storage of soiled or contaminated objects and materials;

ii in locker rooms, toilets, garbage or mechanical rooms;

iii under sewer lines that are not shielded to intercept potential drips; or

iv in the same room/vicinity as chemicals/pesticides.

e. Non-food agents such as disinfectants, detergents, pesticides and other similar products shall be stored separately in a lockable area that prevents the potential for contamination of food, food ingredients, food contact surfaces and non-food materials such as utensils, linens, single-service and single-use utensils, and packaging materials.

f. Personal belongings and uniforms of employees should be stored separately from food storage and food preparation areas.

Rationale:

Contamination of food, food ingredients, equipment, and non-food materials can occur when improper storage facilities are used. Separation of food and equipment from toxic and soiled materials ensures that the opportunity for cross-contamination is minimised. A number of other environmental conditions can lead to contamination or food spoilage. For example, refrigeration condensers located in dry food storage areas can produce heat that may damage foods, including canned goods, unhygienic practices, including poor employee hygiene, can also cause contamination. 


\subsection{Water Supply}

a. An adequate supply of drinking water obtained from a source approved by the Dubai Municipality or Dubai Electricity and Water Authority must be used in the food establishment for cleaning and food preparation purposes;

b. An adequate supply of hot water should be provided for all cleaning activities conducted on the food premises. The hot water supplied should be of sufficient temperature to achieve effective cleaning;

c. Water storage tanks for drinking water should be designed and constructed in a manner that prevents contamination. To prevent the access of animals, birds and other extraneous matters, water storage tanks and over flow tanks should be provided with appropriate covers.

d. Where non-potable water is used for non food purposes, for example for fire control, steam production, refrigeration and other similar purposes, a separate duly identified water supply system should be used. Non-potable water lines should not be connected with drinking water systems.

e. Ice which comes into contact with food has to be made from drinking water. Ice should be made, handled and stored under conditions that protect it from contamination.

f. Steam used directly in contact with food shall not contain any substance that presents a hazard to health or is likely to contaminate the food.

g. Water storage tanks shall be maintained clean at all times. Cleaning and disinfection of tanks should be carried out at least twice per year, but more frequently if necessary. The water tanks should be cleaned only by a cleaning company approved by the Food Control Department.

h. When a storage tank is shared by several food establishments (such as in a mall), the food establishment should be able to show documented evidence that the water tank is cleaned as required.

j. Drinking water coolers and dispensers shall be regularly cleaned and disinfected so as to keep it free of dirt and microbial contamination.

\section{Rationale:}

Water can be a source of food contamination and thus must be of good standard all the time. Even though the water source is good, a bad supply system of storage tank can recontaminate the water before it is consumed. A safe distribution system and regular cleaning and disinfection of water tanks will ensure that the water is clean and safe to drink and also avoid contamination of food or equipment.

\subsection{Sewage and Solid Waste Disposal}

a. Sewage disposal systems shall meet all the requirements of the concerned department of Dubai Municipality.

b. Disposal of sewage and solid waste shall be done in a hygienic manner which does not expose the food premises or food products to potential contamination. 
c. Food establishment should follow the requirements for the separation of various solid-waste streams as outlined by the concerned department of Dubai Municipality. Solid waste containers within the food establishment should:

i be sufficient in number and accessible;

ii be designed to minimise both the attraction of pests, and the potential for airborne contamination;

iii be identified as to their contents;

iv have functional foot operated lids, if closed containers are used.

d. Garbage storage rooms and containers should be emptied, cleaned and disinfected as often as necessary.

e. Solid waste containers/receptacles located outside the premises should be:

i equipped with covers and closed when not in use;

ii maintained in a manner that does not attract pests;

iii located away for the entrance of the food establishment;

iv preferably stored in a pest proof structure.

\section{Rationale:}

The proper disposal of sewage and solid waste is critical in preventing the spread of pathogens in the food premises. In addition, the sanitary disposal of both sewage and solid wastes, and the maintenance of waste containers and facilities, will minimise the presence of pests inside and outside the premises.

Open waste containers can be used in a pest free environment if such bins can be emptied and cleaned frequently. Where bins with lids are used, there is always a human tendency to open the lid with hands. Food handlers should refrain from touching the lids with hands.

\subsection{Grease Traps}

a. Grease traps should, whenever possible, be located outside the premise.

b. Grease traps should be of a suitable type and be regularly inspected. The greasy waste should be promptly removed and the adjoining floor surfaces should be cleaned thoroughly afterwards.

Rationale:

Waste water from food premises carries a large quantity of grease, which will solidify and cause blockages in drains. It must be removed from the water entering the drain. A blocked drain / sewer causes back-flow of waste water and emits bad odour, posing a hazard to food safety and environmental hygiene. 


\subsection{Plumbing System}

a. The plumbing system conveying water and waste requires the approval from the concerned department of Dubai Municipality

b. Where water conditioning devices such as water filters or screens are installed on water lines, they should be of a type that permits easy disassembly, to facilitate periodic servicing and cleaning

c. In order to prevent backflow through cross connections, back-flow prevention devices (e.g. air gaps, vacuum breakers) should be installed wherever required.

Rationale:

Cross connections and backflow can contaminate the drinking water supply.

\subsection{Overhead Utility Lines}

a. Utility lines such as gas, electrical, sewage and water lines, as well as cooling ducts, should be suspended away from work areas or areas of open food to minimise the potential for contamination.

b. They should exhibit no sign of flaking rust or paint.

c. Lines carrying contaminated or hazardous materials, such as sewer or floor drain lines, shall be located sufficiently distant from any product or product contact surfaces to prevent any risk of contamination.

d. Lines should be:

i insulated, where appropriate, to prevent condensation

ii constructed and covered with a suitable material to minimise the build-up of soil

iii easily cleanable; and

iv labelled or colour-coded.

\section{Rationale:}

Conditions such as dripping condensation or excessive dust from overhead utility lines can be a source of contamination when the lines are suspended over work areas or areas of open food. The consequences of contamination due to leakage are significantly greater with lines carrying sewage, hazardous chemicals or highly contaminated materials.

\subsection{Handwash Stations}

a. At least one handwash station shall be provided in each food preparation area. Additional handwash stations may be required depending on the type and extent of activity.

b. Handwash facilities shall:

i be located to allow convenient access and use by food handlers and other workers;

ii be equipped with single-use liquid soap dispensers and paper hand towel dispensers; 
iii provide an adequate flow of water at a suitable temperature (not too cold nor too hot);

iv be easily cleanable, and maintained in a clean and sanitary condition;

$\mathrm{v}$ indicated with clear signboards and not be used for purposes other than hand washing.

Rationale:

Improper hand washing is a major contributing factor to outbreaks of foodborne illnesses. Provision of proper and adequate hand washing facilities is essential to minimising food contamination and maintaining personal hygiene.

The temperature of the water should be suitable to encourage handwashing. If the water is too hot or too cold, employees might have a tendency to avoid handwashing.

\subsection{Toilet Facilities and Dressing Areas}

a. Adequate, suitable and conveniently located toilets should be provided for food handlers. The following criteria should be considered :

i toilets should be conveniently located and accessible to workers during all hours of operation;

ii toilets should be completely enclosed and provided with a tight-fitting and self-closing door;

iii toilets should be equipped with a handwash station; including a liquid soap and paper towel dispenser; have handwashing sign prominently displayed;

iv toilets should be easily cleanable, well ventilated, and well lit; and

$\mathrm{v}$ toilets should not open directly into a food area where food or packaging material is stored, handled or packed;

vi when adjacent to a food area, the toilet should be separated with a double door and ventilated space.

b. Toilet rooms for the public, if provided, should be completely enclosed and separated from the food preparation and storage areas.

c. Dressing and changing areas should be provided if workers routinely change their clothes in the food premises. Dressing and changing areas should be:

i easily cleanable;

ii well ventilated and well lit;

iii provided with lockers or other suitable facilities for the storage of workers' possessions and uniforms;

iv separate for male and female employees. 
Rationale:

Properly located and equipped toilet facilities are necessary to protect the equipment, facility and food from faecal contamination which may be carried by insects, hands or clothing. Toilet facilities, kept clean and in good repair, minimise the opportunities for the spread of contamination.

\subsection{Cleaning Facilities}

a. To meet the cleaning requirements of the operation, every food establishment should have sufficient and suitable cleaning materials, equipment and facilities.

b. The service sink or curbed cleaning facility, equipped with a floor drain, should be conveniently located for the cleaning of mops or similar wet floor cleaning tools, and for the disposal of mop water and similar liquid waste. Such facilities should be located away from food handling areas.

c. Adequate storage facilities should be provided as necessary stored away from food handling areas to store brooms, mops, pails, and cleaning compounds when not in use. Toilets should not be used for storing cleaning materials or equipment.

Rationale:

Liquid waste from wet floor cleaning methods are contaminated with microorganisms and filth. A service sink or curbed cleaning facility with a drain allows for the sanitary disposal of this waste water in a manner that will not contaminate the food. Designated storage areas for brooms, mops, pails, etc., will assist in the sanitary operation of the premises during periods when they are not in use.

\subsection{Exterior Openings}

a. Exterior openings should be protected against the entry of pests. Examples include:

i filling or closing holes and other gaps along the floor, walls and ceiling;

ii solid, self-closing, tight-fitting doors; and

iii screen doors that open outward and are self-closing.

b. If windows or doors are kept open for ventilation or other purposes, the exterior openings should be protected against the entry of pests by means such as screens, properly designed and installed air curtains or other effective means to restrict the entry of pests.

c. Windows, doors and other openings should be constructed in a way that prevents accumulation of dirt.

These provisions may not apply if pests are absent due to the location of the food premises, or other limiting conditions. 
Rationale:

Pests may carry pathogenic organisms on and within their bodies. As the pests move about the operation, these pathogens can spread through the food premises. Freedom from pests reduces the likelihood of contamination of both equipment and food.

\subsection{Temporary Food Establishments}

Temporary food establishments are those types of establishments that are set up with a time-limited life (e.g., special events, fairs and festivals, exhibitions etc.).

a. All specific requirements related to ensuring food safety including the prerequisites such as location, design and layout should be met.

b. A prior approval from the Food Control Department is required to operate such food establishments.

\subsection{Mobile Vendors, Stalls, Catering Trucks, Dinner Cruise, Desert Events}

This requirement covers food establishments including mobile food vans or other similar temporary mobile food businesses, mobile vending operations, and establishments that supply food to cruise ships, desert events and other external events that are permanent or temporary in nature.

a. Food establishments require prior approval from the Department to supply food, and should meet the relevant provisions of this Code depending on the type and extend of the activity.

b. Food establishment should follow relevant temperature requirements and other handling and storage recommendations of this Code. When the food is supplied to a third party such as an event organiser, the food establishment that supplies the food should ensure that handling requirements of food are clearly communicated in writing to the person in charge of the event.

\subsection{Vending Machines}

Vending machines, although technically regarded as "food establishments", often do not require the same level of construction and equipment as full-fledged food establishment. Nevertheless, they do have some specific requirements to ensure the safe storage and dispensing of food and the prevention of health hazards. Operators of vending machine should follow relevant temperature requirements and other handling and storage recommendations of this Code. Adequate measures should be in place to control both intentional and unintentional contamination.

\subsubsection{Liquid Foods and Ice}

In equipment that dispenses or vends liquid food or ice in unpackaged form, the delivery tube, chute and orifice should be designed such that:

a. Splashes and drips (including drips from condensation) are diverted away from the container receiving the food (by means of barriers, baffles or drip aprons, for example).

b. Tubes, chutes and openings are protected from manual contact (by being recessed, for example). 
c. Where the item is dispensed, the equipment is provided with means to prevent back siphonage.

d. Delivery tubes, chutes and openings are protected from dust, insects, rodents and other contamination by a self-closing door if the equipment is:

i located outdoors and is not protected from precipitation, wind-blown debris, pests and other contaminants present in the environment; or

ii available for self-service of food during hours when it is not under the full-time supervision of a food employee.

Rationale:

For vending machines that dispense liquid food or ice, it is important to prevent the entry of condensate or splash, which may contaminate the food product. Food contact surfaces which divert liquid food into the receiving container need to be protected from contact by customers/people to prevent contamination of the food product. A self-closing door on outdoor machines or unsupervised machines further protects against accidental or malicious contamination.

\subsubsection{Self-Service Beverages}

a. Self-service beverage dispensing equipment should be designed to prevent contact between the lip-contact surface of glasses or cups that are refilled and:

i the dispensing equipment actuating lever or mechanism; and

ii the filling device.

b. Beverage equipment that utilises carbonation equipment $\left(\mathrm{CO}_{2}\right)$ should incorporate a back-flow, back-siphonage prevention device (check valves) to prevent the migration of the carbonated beverage into copper water supply lines.

Rationale:

Through proper design of the dispensing equipment, contamination of the lip-contact surfaces of the refillable containers can be avoided, and the risk of cross-contamination reduced. As well, back-flow into water supply lines has resulted in incidents of copper poisoning after consumption of the dispensed beverage.

\subsubsection{Beverages in Paper-Based Packaging}

Vending machines designed to store beverages that are packaged in containers made from paper products should be equipped with diversion devices and retention pans or drains for container leakage. 


\subsubsection{Vending of High Risk Foods}

A machine vending high risk foods shall have an automatic control that prevents the machine from vending food if there is a power failure, mechanical failure or other condition that results in an internal temperature that cannot maintain the food temperature required in this Code.

Note: The automatic control shall prevent the machine from dispensing food until it is restocked and can maintain food at required temperatures.

\section{Rationale:}

Vending machines require a "fail-safe" device that would prevent the dispensing of high risk foods, in the event of mechanical or power failures which could subject them to temperature abuse. 


\section{Control of Hazards in Food}

This part of the food Code is based upon the principle that food safety is best ensured through the identification and control of hazards in the production and handling of food as described in the Hazard Analysis and Critical Control Point (HACCP) system, adopted by the joint WHO/FAO Codex Alimentarius Commission, rather than relying on end product standards alone. The Food Control Department requires all food establishments to implement a risk based food safety programme.

\subsection{Management of Food Safety}

\subsubsection{Management - Person in Charge}

a. All food establishments shall employ at least one (1) full time, on-site Person in Charge (PIC) certified in food safety.

b. All food service establishments where high-risk, ready to eat or raw foods are prepared shall have at least one PIC certified in food safety present in the establishment during all shifts (duration) of food establishment operation. The PIC should be responsible for and should actively oversee all food establishment operations that could have an impact on the safety of the food.

c. Each certified PIC shall possess knowledge of food safety principles and practices as demonstrated by passing a written examination acceptable to the food control department. Each person passing an acceptable examination shall receive a certificate valid for a period of five years from the date of issuance.

d. The name of the PIC should be displayed behind the cash counter or in a place that is clearly visible to customers.

e. Once the employment of a PIC is terminated, establishments can take up-to thirty (30) days to designate a new PIC. The proposed PIC should enrol for the training programme and be certified within 45 days.

\subsubsection{Roles and Responsibilities of Person in Charge}

a. The PIC should be competent and have appropriate knowledge on food safety risks associated with the type of business.

b. The PIC should ensure that the establishment maintains policies and procedures for all employees to follow in order to assure the production, sale, and/or dispensing of safe food products.

c. The PIC should provide effective supervision in implementing safe food practices, conduct regular inspection of the food premises, address potential food risks, and, where necessary, take appropriate corrective action.

d. The PIC should maintain measures of accountability for meeting food safety responsibilities, including ensuring that

i all employees are trained before they start of work; and

ii trained employees are competent and are carrying out responsibilities as required. Training should be provided based on the criteria stipulated under Section 6 of this Code. 


\subsubsection{Food Safety Programmes}

All food establishments should implement and maintain a Dubai Municipality approved food safety programme that is documented and that identifies and controls food safety hazards.

\subsubsection{General Requirements for Food Safety Programmes}

A food establishment should:

a. Systematically examine all of its food handling operations in order to identify the potential hazards that may reasonably be expected to occur.

b. Develop and implement a food safety programme to control the hazard or hazards if one or more hazards are identified in accordance with paragraph (a).

c. Set out the food safety programme in a written document and retain that document at the food establishment.

d. Comply with the food safety programme; and conduct a review of the food safety programme at least annually to ensure its adequacy.

e. Review the system and make necessary changes to it when any significant modification is made to the product, process, or any step, or in the event of a justified food complaint or food related incident.

\subsubsection{Auditing of Food Safety Programme}

All food establishments, unless there is a waiver from the Food Control Department, should

a. Ensure that the food safety programme is audited by a third party food safety auditor approved by Dubai Municipality at an auditing frequency applicable to the food establishment

b. Make the written document that sets out the food safety programme, and the appropriate records available to any food safety auditor who has been requested to conduct an audit of the food safety programme; and

c. Retain copies of all written reports of the results of all audits of the food safety programme conducted by a food safety auditor within the last four years, for inspection upon request by a food safety auditor who audits the food safety programme or an Authorised Officer from Dubai Municipality.

\subsubsection{Content of Food Safety Programmes}

A food safety programme should

a. Include in its scope all foods that are prepared, sold, distributed or displayed in the food establishment.

b. Systematically identify the potential hazards that may be reasonably expected to occur in all food handling operations of the food establishment.

c. Identify where, in a food handling operation, each hazard identified under paragraph (b) can be controlled and the means of control.

d. Provide for the systematic monitoring of those controls. 
e. Provide for appropriate corrective action when that hazard, or each of those hazards, is found not to be under control.

f. Provide for the regular review of the programme by the food establishment to ensure its adequacy; and

g. Provide for appropriate records to be made and kept by the food establishment demonstrating action taken in relation to, or in compliance with, the food safety programme.

\subsection{Food Handling and Processing}

\subsubsection{General requirements for processing food}

a. Food establishments must take all practicable measures to process only safe and suitable food.

b. Food establishments when processing food should;

i take all necessary steps to prevent the likelihood of food being contaminated; and

ii where a process step is needed to reduce to safe levels any pathogens that may be present in the food, use a process step that is reasonably known to achieve the microbiological safety of food.

c. A food establishment, when handling and processing high risk food that will not undergo a pathogen reduction step, ensure that the time the food remains at temperatures that permit the growth of infectious or toxigenic bacteria in the food is minimised.

\subsubsection{Food Source}

A food establishment shall take all practicable measures to ensure it only accepts food that is not contaminated.The PIC should provide information, i.e. a specification, to suppliers for each ingredient, where necessary, to ensure the desired safety and quality of those foods and ingredients on delivery.

\subsubsection{Approved Sources}

Food and food ingredients received at a food establishment shall be obtained from sources that are approved by Food Control Department. Approved food sources are establishments that are licensed to operate in the United Arab Emirates and are inspected by the respective Emirate's Food Control agency.

a. Food establishments should provide, to the reasonable satisfaction of an authorised officer upon request, the following information relating to food, the name and business address of the supplier, vendor, manufacturer or packer or, the importer.

b. Food establishments that serve raw or lightly cooked (such as raw oysters, sushi, kebeneyah steak tartar, carpaccio), should obtain detailed information from the supplier on the source and probable levels of microbial contamination. Relevant records should be maintained as evidence of action.

\section{Rationale:}

Safe food starts with reputable and reliable food suppliers who meet food hygiene and safety standards. These suppliers operate in a manner that prevents and controls contamination of foods and ensures the foods are safe for human consumption 


\subsubsection{Unapproved Sources}

Food prepared in a private home, unlicensed establishments or any other place, which is not approved by the Food Control Department, shall not be commercially offered for human consumption.

\subsubsection{Food Receiving}

Foods that are imported to the different Emirates are inspected by the respective regulatory agencies at the port and then released to the market. Instructions provided at the time of the release should be followed by the importing establishment and the release documents should be verified by the retail establishments. Food establishments should always verify that their supplies are delivered safely.

\subsubsection{Inspection of Incoming Food}

a. Inspection should be carried out at the time of receipt of food from the supplier to ensure that:

i Food and packaging are free from visible damage, pests and other contaminants; and that they are protected from contamination;

ii food is in an appropriate condition for intended use;

iii food is accompanied by appropriate documentation;

iv transport is suitable, and approved by concerned food authority.

b. Foods that require temperature control for safety are to be delivered at temperatures stipulated in section 3.6 of this Code.

c. Food containers and packages should be intact and free from damage.

d. Food items should be properly labelled - ingredient listing, date coding etc.

e. If the food is pre-packaged, the time gap between the date of receiving and expiration date should be sufficient to use the product and avoid wastage of stock.

f. Unacceptable food should be returned and documented.

g. Food products should be quickly moved into storage after the inspection.

Rationale:

Food contaminated with pathogenic microorganisms, chemicals and foreign matters may compromise food safety. Therefore, food establishment should not accept food known (or suspected) to be contaminated with these substances.

Most pathogenic bacteria grow and multiply rapidly at temperatures between $5^{\circ} \mathrm{C}$ and $60^{\circ} \mathrm{C}$. At temperatures lower than $5^{\circ} \mathrm{C}$ and higher than $60^{\circ} \mathrm{C}$, bacterial growth slows down or stops. However, there are bacteria that can grow slowly up to a temperature of $-2^{\circ} \mathrm{C}$ and most bacteria can survive cold temperatures and resume multiplication later when conditions become suitable again. This range of temperatures between $5^{\circ} \mathrm{C}$ and $60^{\circ} \mathrm{C}$ is normally called the TEMPERATURE DANGER ZONE. High risk food may be contaminated by pathogenic bacteria which can multiply to dangerous levels at ambient temperatures. As such, high risk food should be kept at or below $5^{\circ} \mathrm{C}$, or at or above $60^{\circ} \mathrm{C}$ during delivery, to prevent growth of these bacteria. The temperature of the food may go up during the delivery time, but this time should be as short as possible. 
Freezing is a process in which the temperature of a food is reduced below its freezing point and the majority of the water inside the food undergoes a change in state to form ice crystals. Freezing preserves food for extended period of time by preventing the growth of micro-organisms that cause food spoilage and foodborne illnesses. To maintain the quality of frozen food, a temperature of $-18^{\circ} \mathrm{C}$ or less is preferred.

\subsubsection{Product Identification}

a. All food products received at a food premise should be properly packaged and labelled, according to requirements outlined by the Food Control Department or any other relevant standard such as the Gulf Standards.

b. Invoices, receipts, and lot coding information should be retained, to allow tracking of unlabelled products (such as raw fish, oyster, carcasses, produce or bakery products) or split lots.

c. In retail food service establishments such as restaurants and catering establishments, if the original packaging of the food is removed after receiving, the same production and expiration dates on the original label should be marked on the new label. The establishment should have a documented internal policy for date marking of products that are stored after the removal of the original packing. However, the foods that are consumed or heat processed on the same day need not meet this requirement.

Rationale:

A food establishments should be able to identify the food that they have in the premises in order to facilitate tracing products in the event of a recall or a food incident. The information can be obtained from an invoice, receipt or the packaging of the food when necessary and such documents should be retained for a particular duration not less than the shelf life of the product.

\subsubsection{Ingredient inspection and control}

a. All ingredients used in food preparation should be inspected prior to their use.

b. Any ingredients that are off-colour, have strange odours, show evidence of pest contamination or suspected to be contaminated in any other manner should be discarded.

\subsubsection{Food Additives}

a. Food additives that are banned by the Food Control Department shall not be used.

b. All additives shall be used at a concentration recommended in the relevant product standard. In the absence of a standard, scientific validation is necessary.

c. Manufacturers and suppliers of food additives should provide information on safe usage of additives to the end user.

d. Food handlers who handle additives should be appropriately trained to use additives. 


\subsubsection{Handling Raw Food}

a. Raw and ready-to-eat foods should be kept separate at all times. Contamination of ready to eat foods should be prevented using methods outlined in section 3.4 of the Code.

b. Fruits and vegetables that are consumed raw should be cleaned and disinfected using a chemical disinfectant or any other process approved by the Food control Department.

\subsubsection{Handling of Chilled and Frozen Food}

a. Food establishments shall meet the provisions of section 3.6 of this Code during receiving, storage and preparation of frozen and chilled foods.

b. Provisions of section 3.3 should be used during preparation and handling of high risk foods at ambient temperature. It is strongly recommended that areas used for preparation of cold high risk foods should be maintained at $20^{\circ} \mathrm{C}$ or below to minimise bacterial multiplication.

\subsubsection{Thawing}

Frozen foods should be thawed quickly in a manner that will prevent the rapid growth of pathogenic and spoilage bacteria. During the process of thawing, the microbiological count should not exceed the limits specified in the relevant product standard.

a. When thawing high risk frozen foods, the warmest portion of the food shall not rise above $5^{\circ} \mathrm{C}$ and the food should be used within 48 hours from the time of start of thawing.

b. Frozen raw meat, poultry and fish may be thawed under refrigeration at air temperature of $10^{\circ} \mathrm{C}$ or less, or under cold running water, as long as the product temperature does not exceed $5^{\circ} \mathrm{C}$. If the raw food is not to be cooked/prepared immediately after thawing, it should be stored below $5^{\circ} \mathrm{C}$. Such foods should be cooked within 72 hours from the time of the start of thawing.

c. Frozen raw meat, poultry and fish when cooked immediately after thawing, can be thawed using methods where the thawed portions of the foods are above $5^{\circ} \mathrm{C}$. The time period above $5^{\circ} \mathrm{C}$, including the time for preparation prior to cooking does not exceed 4 hours. A prior approval from an authorised officer of Food Control Department will be required for this process.

d. Raw meat, fish or poultry thawed at a temperature that does not exceed $5^{\circ} \mathrm{C}$ can be refrozen for specific processes with prior approval from an authorised officer of Food Control Department.

Note: Hazards associated with thawing include cross-contamination from drip and growth of microorganisms on the outside before the inside has thawed. Thawed meat and poultry products should be checked frequently to make sure the thawing process is complete before further processing or the processing time should be increased to take into account the temperature of the meat.

\section{Rationale:}

Freezing prevents microbial growth in foods, but will not destroy most microorganisms. Improper thawing provides an opportunity for surviving bacteria to grow to harmful numbers and/or produce toxins. Complete thawing of raw food helps to prevent undercooking. 


\subsubsection{Cooking Raw Foods of Animal Origin}

a. The time and temperature of cooking raw foods of animal origin and food mixtures containing raw foods of animal origin should be sufficient to reduce any food borne pathogen that may be present in the food to an acceptable level.

b. Raw foods of animal origin and food mixtures containing raw foods of animal origin shall be cooked until core temperature is at least $75^{\circ} \mathrm{C}$ or to a time and temperature that would give an equivalent pathogen reduction. The nature of the product must be taken into consideration when defining the equivalent time and temperature requirements

c. Cooking temperature should be checked regularly by inserting a calibrated thermometer into the slowest heating point, normally the core of a product, and the temperature readings recorded.

Rationale:

To kill microorganisms, food should be held at a required temperatures for specified times. Different species of microorganisms have varying susceptibilities to heat. As well, food characteristics affect the lethality of cooking temperatures. Heat penetrates into different foods at different rates. High fat content in food reduces the effective lethality of heat. High humidity within the cooking vessel and the moisture content of food aid thermal destruction. Heating a large roast too quickly with a high oven temperature may char or dry the outside, creating a layer of insulation that shields the inside from efficient heat penetration. To kill all pathogens in food, cooking should bring all parts of the food up to the required temperatures for the correct length of time.

\subsubsection{Raw Ready to Eat Foods of Animal Origin}

Where animal or sea food is served raw or lightly cooked (such as sushi, raw oysters, steak tartar, carpaccio, sweets and shakes made from raw eggs etc.), the following measures should be taken:

a. The food safety programme should identify the risks and both validate and verify the effectiveness of the control measures implemented to reduce the risk.

b. When raw fish or meat is served to the consumer, the establishment should have in place control measures to eliminate parasites and reduce the presence of other pathogens to an acceptable limit.

c. When it is not obvious to the consumer that the food or the ingredient is raw, the menu or the label on the packaging should clearly state the name of the ingredient and also state that the ingredient is raw.

d. When packed and sold, the packaging should clearly state the storage and handling requirements necessary to ensure safety of the food.

\subsubsection{Hot Holding}

a. Cooked foods to be served hot, shall be held at a temperature of at least $60^{\circ} \mathrm{C}$.

b. Appropriate hot holding devices should be used to maintain high risk foods at the correct temperature. 
Note: Surface cooling of hot food can be controlled by keeping hot food covered as much as possible. To minimise the loss of the organoleptic properties and nutritional quality of the food, it is recommended that food should be kept at or above $60^{\circ} \mathrm{C}$ for not more than 4 hours.

Rationale:

No pathogenic bacteria multiply in food that is $60^{\circ} \mathrm{C}$ or above.

\subsubsection{Cooling after Cooking}

a. Cooked high risk foods intended to be kept under refrigerated storage prior to serving, are to be cooled from $60^{\circ} \mathrm{C}$ to $20^{\circ} \mathrm{C}$ or less within two hours and then from $19^{\circ} \mathrm{C}$ to $5^{\circ} \mathrm{C}$ or less within 4 hours (total 6 hours).

b. Foods that are cooled this way and stored chilled should be used within 72 hours from the time of preparation.

Note: Food stays at the danger zone for more than 2 hours during cooling. Rapid cooling prevents multiplication of bacteria and this is an exceptional situation.

There are some ways that can help to cool food rapidly:

- reduce the volume of the food by dividing it into smaller portions and / or placing it in shallow containers;

- cut large joints of meat and poultry into smaller chunks before cooking; and

- When cooling equipment is used, ensure there is space around the food containers so that the cold air in the refrigerator or cool room can circulate freely.

Rationale:

Temperatures achieved during cooking should be sufficient to destroy vegetative cells of pathogens; however, some spores are unaffected. In some cases, cooking activates spores which may germinate during subsequent cooling.

Excessive time for cooling of high risk food is one of the key contributing factors to foodborne illnesses. During extended cooling, foodborne pathogens that may contaminate cooked food or developed from surviving spores may grow to a sufficient number (and / or produce toxins) to cause illnesses. By reducing the cooling time, the risk for pathogenic bacteria to grow to a dangerous level (and / or producing toxin) will be minimised.

If the cooking step prior to cooling is adequate and no recontamination occurs, all but the spore-forming organisms such as Clostridium Perfringens should be killed or inactivated. However, under poorly monitored conditions, other pathogens such as Salmonella may be reintroduced. Thus, cooling requirements have been based on growth characteristics of organisms that grow rapidly under temperature abuse conditions.

Large food items such as roasts, turkeys and large containers of rice, take longer to cool because of the mass and volume from which heat shall be removed. By reducing the volume of the food in an individual container, the rate of cooling is dramatically increased and opportunity for pathogen growth is minimised. Commercial refrigeration equipment is designed to hold cold food temperatures, not cool large masses of food. 


\subsubsection{Cooling from Room Temperature}

When high risk foods are prepared at room temperature and kept under refrigerated storage prior to serving, they should be cooled from room temperature to $5^{\circ} \mathrm{C}$ or less within 4 hours. This includes those foods whose ingredients were canned or made from reconstituted foods.

\subsubsection{Reheating Cooked Foods for Hot Holding}

a. Cooked foods that are cooled and stored at $5^{\circ} \mathrm{C}$ and are intended to be held and served hot should be reheated until it reaches an internal temperature exceeding $75^{\circ} \mathrm{C}$ in a manner that they will pass through the danger zone $\left(5^{\circ} \mathrm{C}\right.$ to $\left.60^{\circ} \mathrm{C}\right)$ as quickly as possible. Reheating time should not exceed 1 hour.

Rationale:

Pathogenic bacteria may be present in cooked food due to germination of surviving spores or postcontamination after cooking. These pathogens can grow during cooling and cold storage. Proper reheating provides a major degree of assurance that pathogens will be eliminated. It is especially effective in reducing the numbers of Clostridium Perfringens that may grow in meat, poultry or gravy if these products were improperly held. The generation time for C. Perfringens is very short at temperatures just below adequate hot holding.

The potential for growth of pathogenic bacteria is greater in reheated foods than in raw foods. This is because spoilage bacteria, which inhibit the growth of pathogens by competition on raw products, are killed during cooking. Subsequent recontamination will allow pathogens to grow without competition if temperature abuse occurs.

It should be noted that reheating cannot make high risk food safe if it has not been cooled properly or protected from contamination. This is because some pathogenic bacteria (such as Staphylococcus Aureus) may continue to multiply and produce heat stable toxins under such circumstances. Reheating such food to $75^{\circ} \mathrm{C}$ cannot destroy the toxins.

Cooked food that has been reheated should not be cooled and reheated for a second time to avoid it from repeatedly exposed to temperatures that can support the growth of pathogenic bacteria.

\subsubsection{Reheating Cooked Food for Immediate Service}

a. Cooked foods that are cooled and stored at $5^{\circ} \mathrm{C}$, can be reheated once only and served, if for immediate consumption, at any temperature, provided the time the food spent between $5^{\circ} \mathrm{C}$ and $60^{\circ} \mathrm{C}$ does not exceed 2 hours.

b. Reheated cooked foods should not be re-cooled for further use.

\section{Rationale:}

Many foods are at risk during preparation and service. As foods are thawed, cooked, held, served, cooled, and reheated, they pass several times through the temperature danger zone. The amount of time that cooked foods are in the danger zone will have an impact on the safety of the product. 


\subsubsection{Use of Microwave for Cooking or Reheating}

Cooked and cooled food reheated in microwave, should be rotated or stirred throughout or midway during cooking to compensate for uneven distribution of heat, and allowed to stand covered for a minimum of 2 minutes after cooking to obtain temperature equilibrium.

Rationale:

The rapid increase in food temperature resulting from microwave heating does not provide the same cumulative time and temperature relationship necessary for the destruction of microorganisms as do conventional cooking methods.

Since cold spots may exist in food cooking in a microwave oven, it is critical to measure the food temperature at multiple sites when the food is removed from the oven, and then allow the food to stand covered to allow thermal equalisation and exposure.

\subsubsection{Canning}

Low-acid canned foods should be cooked to a temperature of $121^{\circ} \mathrm{C}$ for a minimum of 3 minutes or subject cans to an equivalent process that would ensure the destruction of spores of Clostridium Botulinum.

\subsubsection{Use of Non-thermal Processes for Pathogen Reduction}

Non-thermal processes can be used in specific applications intended to minimise organoleptic changes that are caused by thermal processes.

\subsubsection{Controlling Growth of Pathogens with Water Activity and Acid Ingredients}

a. Foods that have a water activity of 0.91 or less can be stored without temperature control.

b. Foods that have a $\mathrm{pH}$ of less than 4.0 can be stored safely without temperature control.

c. Such processes when used shall be validated and the control measures verified frequently.

\subsection{Time as a Safety Control}

High risk foods should be stored under temperature control at all times. However, time can be used as a safety measure during exceptional situations where temperature control is not possible. However, food service establishments that routinely hold food before service must use temperature control for safety.

a. High risk hot foods that are intended for immediate consumption shall not be stored, displayed or held for service at temperatures between $5^{\circ} \mathrm{C}$ and $60^{\circ} \mathrm{C}$ for a period of more than 2 hours. The food product shall be discarded after that time.

b. High risk cold foods that are intended for immediate consumption shall not be stored, displayed or held for service or display at temperatures between $5^{\circ} \mathrm{C}$ and $60^{\circ} \mathrm{C}$ for a period of more than 4 hours including the time of preparation. The food item should be discarded after that time. After preparation, the food should be quickly chilled to $5^{\circ} \mathrm{C}$ before it is displayed. 
c. Foods stored without temperature control under section (a) and (b) above should be clearly labelled with the time of expiration to indicate the time when the food has to be discarded.

Rationale:

Food establishment should keep high risk foods at either $5^{\circ} \mathrm{C}$ or below, or $60^{\circ} \mathrm{C}$ or above, during storage, display and transportation. However, it is acceptable for high risk food to be kept out of temperature control (i.e. between $5^{\circ} \mathrm{C}$ and $60^{\circ} \mathrm{C}$ ) for a limited time because pathogens (and / or toxin production) need time to grow to an unsafe level. The total time is the sum of the time the food is at temperatures between $5^{\circ} \mathrm{C}$ and $60^{\circ} \mathrm{C}$ after it has been cooked (or processed) to make it safe. It does not include the time taken to cool the food after cooking, provided, the food has been rapidly cooled within the required time and temperature.

\subsection{Preventing Food and Ingredient Contamination}

\subsubsection{Preventing Microbial Contamination}

a. Access to food preparation areas should be restricted, as much as practically possible, to designated people.

b. For visitors including management and maintenance staff, all practicable measures should be taken to ensure that they will not contaminate food when visiting food preparation areas.

c. Where the public has access to food other than raw, unprocessed fruit and vegetables, or food specifically served to a customer by a worker of the food premises, the food should be protected from public handling and contamination by the use of packaging, display cases, or salad bar sneeze guards (food guards), and be provided with suitable utensils or effective dispensing methods.

d. Food handlers should avoid contact with exposed areas of ready-to-eat foods with their bare hands and use, as much as practically possible, disposable gloves and clean and disinfected utensils such as tongs, spatulas, or other food dispensing apparatus.

e. Raw or unprocessed food should be kept separate from ready-to-eat foods.

f. Ready-to eat foods should not be stored below raw animal products or vegetables.

g. During thawing, drips from thawing food should be prevented from contaminating other foods.

h. Raw fruits and vegetables should be, thoroughly washed in potable water to remove soil and other contaminants, disinfected when necessary, before being cut combined with other ingredients, cooked, served, or offered for human consumption in ready-to-eat form. This does not apply to whole raw fruits and vegetables that are intended for washing by the consumer following point of sale.

i Cleaning and disinfection of food contact surfaces between uses should be carried out as described in Section 4 of this Code. Food should not come into contact with surfaces of utensils and equipment that have not been cleaned and disinfected in accordance with procedures described in this Code.

j. When workers must taste the food, only cleaned and disinfected utensils should be used, and the utensils should be immediately cleaned and disinfected after tasting and prior to tasting another food or the same food. 
k. Foods that have been previously purchased and returned to the retailer or food service operation may not be re-offered for sale to another consumer.

1. Separately marked or colour Coded cutting boards should be used for the preparation of :

i ready to eat foods

ii raw, ready to eat animal and sea food (e.g.. Fish for Sushi);

ii. raw vegetable foods intended to be cooked;

iii. raw animal foods intended for cooking.

m. Separate, freshly cleaned and disinfected food contact surfaces ( including preparation tables, cutting boards and knives) should be used for ready-to-eat foods.

n. Equipment with any raw food contamination should never be used for ready to eat food without being cleaned and disinfected.

o. Food transported in conveyors, elevators or similar means should be protected from contamination.

Rationale:

The food industry faces the threat that the food it serves may endanger workers or customers. Microbes are everywhere. Pathogenic microorganisms pose the greatest danger by causing foodborne illnesses. Good policies and procedures for preventing microbial contamination serve as barriers to these disease-causing organisms.

\subsubsection{Physical and Chemical Contamination}

a. The operator of a food premise should ensure that food is stored, displayed, prepared and served in a manner that prevents the food from becoming contaminated.

b. Non-food items such as chemicals, pesticides or any other substance that can harm consumers must be stored in designated areas away from any food, food equipment or food contact surfaces.

c. Foods may not contain unapproved food additives or food additives in excess of the amounts stipulated under relevant food standards.

\subsubsection{Management of Allergens}

a. Food service establishments must declare the most common ingredients known to cause allergenic reactions when they are present in the food that is prepared or sold in the establishment.

b. Following ingredients are contained in food-whether as an ingredient, compound ingredient, food additive or processing aid-they must be declared on the label or the menu, no matter how small the amount:

i crustaceans and their products (e.g. prawns);

ii peanuts and their products;

iii soybeans and their products;

iv tree nuts and their products;

$\mathrm{v}$ sesame seeds and their products; 
vi fish and fish products;

vii egg and egg products;

viii milk and milk products;

ix gluten and cereals containing gluten (wheat, rye, oats, barley and spelt).

c. If such foods are packaged or re-packaged, the food establishment must list the presence of these substances in the ingredient list on the label.

d. Where the food is prepared for immediate consumption and is exempt from labelling, the required allergen information must either be displayed on, or provided to the purchaser upon request.

e. When preparing and storing allergen free food products, cross-contamination should be prevented by:

i not using the same knives, utensils or chopping board used for foods that are deemed as allergens;

ii not using the same cooking equipment (such as deep fryers, grills, sandwich makers);

iii not storing allergen ingredients with or near non-allergen ingredients (such as in the same refrigerator, storage shelf);

iv not handling allergen free food before washing hands and contact surfaces properly;

f. Retail food service establishments such as restaurants, cafés, cafeterias and coffee shops that offer allergen free food shall check all ingredient labels of food products used in the production of food products for the presence of common food allergens. Handling of such products should be specifically included in the food safety programmes.

g. Food establishments that offer allergen free food should verify the accuracy of the ingredient declarations on the product labels, and the implementation of suitable prerequisite controls such as separation and cleaning to prevent allergen contamination.

h. Food service establishment that offers allergen free food should have at least one competent person on every shift available to deal with customers who are allergic to certain types of food.

\section{Rationale:}

Cross-contamination must be considered in all food establishments. Although a particular food product does not contain allergens, cross-contamination may occur when processing an allergen-free food product with or near another food product which does contain an allergen. Customers who are very sensitive can suffer an allergic reaction even if only a very small amount of an allergen is present.

\subsection{Packaging}

Food packaging should be of suitable design to provide the necessary protection to the product during its shelf life.

\subsubsection{General Requirements for Packaging Materials}

a. Packaging materials should be appropriate for the food to be packed and sufficiently durable to withstand the conditions of processing, storage and transportation. 
b. Packaging materials should not pose a threat to the safety of the food to be packed.

c. Packaging materials and design should provide adequate protection for the food to be packed to minimise contamination and prevent damage.

d. Packaging of food should be carried out under hygienic conditions to protect the food from risks of contamination.

e. Packaging and wrapping of food should be carried out by staff with appropriate training in food safety.

f. Packaging materials should be stored and handled under hygienic conditions to minimise the risks of contamination and deterioration.

Rationale:

In addition to prolonging shelf-life, retaining quality and nutritional values as well as providing a water vapour / gas barrier, packaging is important for preventing food from being contaminated with chemicals, physical matters and bacteria.

Packaging materials should not endanger the safety and suitability of the food in contact with them. They should be suitable for the food to be packed, non-toxic, durable and clean. Chemicals from packaging materials should not migrate into the food; and if migration occurs, there should be no known toxic effects to consumers.

Packaging materials may contaminate food if they are not clean. They should thus be kept in their original packages and stored in clean areas where they are not exposed to risks of contamination.

\subsubsection{Protection of Food Content}

Food packages should be in good condition and protect the integrity of the contents so that the food within is not exposed to adulteration, damage or potentially harmful contaminants.

\subsubsection{Reduced Oxygen Packing}

a. Food establishments that package high risk foods using a reduced oxygen packaging method shall have measures in place to control the growth and toxin formation of Clostridium Botulinum and the growth of Listeria Monocytogenes.

b. Packaging materials or atmospheric packaging gases, where used:

i should not cause harm to people exposed to them;

ii should not pose a threat to the safety and suitability of food under the specified conditions of storage and use.

\subsubsection{Food Containers}

a. The operator of a food establishment should ensure that only food grade containers are used.

b. High-acid foods ( $\mathrm{pH}$ below 4.6) should not be stored or cooked in containers coated with, made of, or containing:

i lead or lead-based products, including lead-glazed ceramics, china, crystal or pewter; 
ii zinc, such as galvanised containers;

iii enamelware, which may chip and expose the underlying metal;

iv copper and copper alloys such as brass; and

$\mathrm{v}$ cast iron;

vi aluminum.

c. Cast iron may be used only under the following conditions:

i as a surface for cooking;

ii in utensils for serving food, if the utensils are used only as part of an uninterrupted process from cooking through service.

\subsubsection{Reusable Packaging}

Reusable packaging materials should be durable, clean, and be able to withstand disinfection process.

\subsubsection{Storage of Packaging Supplies}

Packaging supplies should be stored in a way that they are protected from any form of contamination.

\subsubsection{Returnables, Cleaning-for-Refilling}

a. Except as specified in (b), returned empty containers intended for cleaning and refilling with food, should be cleaned, disinfected and refilled only in a regulated food processing plant.

b. Food specific containers for beverages only may be refilled in a food establishment, if:

i the beverage is not a high risk food;

ii the design of the container, the rinsing described in (iii), and the nature of the beverage, when considered together, allow for effective cleaning at home or in the food premises;

iii facilities for rinsing the containers with potable hot water under pressure are part of the dispensing system.

Rationale:

Separating food from non-food items by creating designated storage areas will ensure that accidental contamination from foreign matter (dirt, broken glass and crockery, and other objects) and toxic chemicals (cleaning agents, , disinfectants, sanitizers, detergents, pesticides) will be minimised.

Chemical contamination can occur during cooking or storage when certain metals contact high-acid foods. Potentially toxic metals include lead, copper, brass, zinc coating, antimony, and cadmium. Some foods that have been involved in metal poisoning are sauerkraut, tomatoes, fruit gelatine, lemonade, fruit punches, and carbonated beverages.

Damaged or incorrectly applied packaging may allow the entry of foreign matter or other contaminants into the food. Canned foods should be closely inspected for imperfections or damage, such as punctures, bulging or seam defects. 


\subsection{Storage, Transportation and Distribution of Food Products}

To ensure continuation of food safety storage and transport facilities need to be designed and managed to protect food products from potential contamination and damage, and to prevent the growth of pathogens.

\subsubsection{Food Transportation, Storage and Distribution Units}

a. Food transportation, storage and distribution units should be designed, constructed, maintained and used in a manner that permit effective segregation of different foods and protects food products from being contaminated.

b. Where both food and non-food products are transported, stored and distributed together, procedures should be in place to ensure that food products are not exposed to potential contamination from non-food products.

c. Food transportation equipment that is intended to be in direct contact with food products shall be constructed with non-toxic materials, which are easy to maintain and clean. Examples include stainless steel and food-grade plastic containers.

d. When necessary, cleaning and disinfection should be done between loading food stuff.

e. where appropriate, cargo containers should be marked for, and used for 'food use only'

f. Food must be transported in vehicles approved by the Food Control Department. Such vehicles should only be used for transporting foods as specified in the approval.

g. Food transportation and storage units/equipment must be of suitable capacity and should be maintained at temperatures that are consistent with requirements of this Code.

h. Equipment units must have accurate and reliable monitoring devices. All such devices should be calibrated at a pre-determined interval.

i. In transportation, storage and distribution units, foods should be stored off the floor and away from walls.

\subsubsection{Temperature Control during Storage and Transportation}

a. All high risk and perishable foods requiring temperature controlled environments to extend their shelf life or limit microbial growth shall be transported, stored or distributed in equipment that consistently maintains those temperature controls.

i at or below $5^{\circ} \mathrm{C}$ if cold or at or above $60^{\circ} \mathrm{C}$ if hot ;

ii frozen at $-18^{\circ} \mathrm{C}$ if they are intended to be stored frozen;

b. Areas used for the storage of dry food commodities need to be cool, well ventilated with a relative humidity of $60-65 \%$, to ensure that product quality and safety is not compromised. Temperature of storage should meet the requirements of the manufacturer when specified on the product label ( for e.g.. Infant formula should be stored below $25^{\circ} \mathrm{C}$ ). 
Rationale:

Temperature control is an effective way to prevent microbial growth and product deterioration. Temperature abuse during transportation, storage or distribution increases the potential for foodborne illness. Food starts to deteriorate as soon as the crop is harvested or the animal is slaughtered. The rate of deterioration is related to the growth of spoilage bacteria and mould. Hence, food should be stored under the right environmental conditions (e.g. suitable temperature, humidity, lighting and atmosphere) to minimise the growth of these micro-organisms and to prevent food from becoming unsafe or unsuitable during the expected shelf- life. Proper storage preserves and prolongs shelf-life of raw food materials and prevents them from contamination by food poisoning bacteria, chemicals and foreign bodies that may finally render the food materials or products unfit for processing or human consumption. Proper storage is one of the essential steps for preventing food from becoming contaminated.

\subsubsection{Handling and Transfer of Foods}

a. Food establishment should take necessary steps to inspect foods at the time of receiving to detect and avoid foods that are unacceptable.

b. Receipt of high risk foods should be monitored to ensure that proper temperatures are maintained during their transportation, storage and distribution. Products and records should be checked at the time of receiving and nonconforming products should not be accepted.

c. Food should not be handled or transferred in any way that may cause damage, contamination or adulteration of the food. Food handlers responsible for loading foods into vehicles, and filling display chillers and freezers should be familiar with capacity levels and restrictions to loading such units, volume limits, air flow, temperature range variances, etc., in order to maintain the minimum/ maximum temperature needs of the products being placed therein.

d. While transferring chilled foods, foods should be quickly moved into temperature controlled storage, to minimise the time in which they are in the danger zone, between $5^{\circ} \mathrm{C}$ and $60^{\circ} \mathrm{C}$. A deviation of not more than $5^{\circ} \mathrm{C}$ is allowed for not more than 20 minutes during the transfer of chilled foods.

e. While receiving and transferring raw frozen foods, the temperature of the food shall not exceed $-10^{\circ} \mathrm{C}$.

f. Contaminated or adulterated foods and foods that have been subject to temperature abuse shall be discarded or disposed off.

g. Damaged food container systems must be thoroughly examined and if the food is contaminated or adulterated, it shall be discarded or effectively segregated until returned to the supplier or otherwise disposed off.

\section{Rationale:}

Careful inspection of transported food will help to minimise the potential of contamination or deterioration of the food product. Prompt handling of foods being transported, stored or distributed serves to minimise the amount of time that perishable foods are in the "danger zone" for growth of pathogenic organisms. Minimising the amount of handling also minimises the chance of contamination. 


\subsubsection{Storage Procedures}

a. Rotation of food stocks in storage areas should occur frequently to ensure that the "first-in-firstout" rule is followed. Food products removed from storage should always be the oldest food stocks present.

b. Food should be stored in suitable and safe containers and stored covered. If packaged, suitability of packaging should be ensured.

\section{Rationale:}

Food that is kept for a long time is also likely to become spoiled and attract pest infestation. Effective stock rotation, to ensure that first-come is used first, is essential to avoiding spoilage and preventing pest infestation. In addition, good stock rotation has the advantage of helping to keep the correct levels of stock.

\subsubsection{Disposal of Food}

Food that has been found or suspected to be unsafe or unsuitable (e.g. food that is subject to recall or has been returned, temperature abused, contaminated or damaged) shall be rejected or identified (e.g. marked, labelled, kept in a separated container or isolated area), kept separately and disposed off as quickly as possible. It shall never be used for human consumption. Details of rejected items shall be documented.

Rationale:

Food intended for disposal should be kept separate so that it is not accidentally sold or used. 


\section{Cleaning and Maintenance}

Establishment cleaning and maintenance includes the elements of cleaning and disinfection, pest management, waste management, building and equipment maintenance and the need to monitor the effectiveness of these elements. Food establishments should ensure that food premises, fixtures, equipment and utensils are maintained to an acceptable standard of cleanliness, and in a good state of repair.

Rationale:

Buildings, materials, utensils and equipment in a food premises, including waste water and refuse collection systems present a potential source of contamination of food and food products. These areas should be kept clean, free of pests and maintained in good order.

Equipment, materials and utensils that come into contact with foods, especially raw products (fish, meat, vegetables, and poultry) are generally considered to be contaminated by microorganisms. These microorganisms could contaminate other products. For this reason, it is necessary to have well established programmes in place to ensure that physical structures, including equipment and utensils, are maintained in a clean and sanitary condition. In order to achieve thorough disinfection, equipment may require dismantling, cleaning and disinfecting at the end of each day or more frequently to prevent microbiological proliferation.

\subsection{General Requirements Pertaining to Maintenance}

a. All parts of the premises, fixtures, fittings and equipment should be maintained at all times in a state of good repair and working condition to:

i prevent contamination of food by plaster, paint, broken glass or leaking pipes, etc.

ii enable effective cleaning and, if necessary, disinfection;

iii ensure pests cannot gain access to the premises from hollow spaces in ceilings, walls, etc.

iv ensure that the equipment works as intended.

b. Floor surfaces should be maintained in good condition, free of cracks, crevices or other defects. There should be no dips or hollows. Floors should be free from accumulation of food waste, dirt, grease or other visible obnoxious matter. They should be washed with detergents at least once daily. Hot water or steam may be used for better removal of grease. Coving between floor and wall junctions should be kept clean, in good repair and be bonded firmly to their positions.

c. Walls of food rooms should be cleaned frequently, daily or more if necessary. Wall surfaces or ceilings should be clear of unnecessary fittings or decorations such as unnecessary posters or pictures as far as possible.

d. Junctions between walls, and between walls and ceilings, should be tightly sealed and maintained in good condition, and free from cracks, crevices, holes or gaps or flaking materials. Any holes or gaps that may allow access of pests to wall and ceiling cavities should be sealed up. False ceilings should be cleaned to remove accumulation of dust, particles or debris that may fall on to foods as to cause contamination. 
e. Any furniture or equipment, which cannot be moved by one man, should not be placed too near to any wall inside kitchens or food preparation rooms as to obstruct access to such places for cleaning. Alternatively, heavy equipment can be installed with wheels to facilitate easy removal for cleaning.

f. Food contact surfaces of equipment and utensils, such as crockery, cutlery and tableware, should be maintained in a good state of repair and working condition. They should be smooth, free of cracks and crevices, and be kept clean and free from noxious matter.

g. Cutting surfaces such as chopping blocks and cutting boards which are subject to scratching and scoring should be resurfaced if they become too difficult to be effectively cleaned and disinfected, and should be discarded if resurfacing is impossible.

h. Non-food contact surfaces of equipment such as cupboards, refrigerators, wet refrigerators, racks, stoves, cooking ranges and food lifts should kept clean and in good state of repair and working condition. They should be free of unnecessary ledges, projections and crevices; and designed and constructed to allow easy cleaning and to facilitate maintenance.

\subsection{Cleaning and Disinfection}

\subsubsection{General Requirements Pertaining to Cleaning}

a. Food contact surfaces of equipment and utensils should be kept clean and free from noxious matters by regular cleaning and disinfection at a frequency that prevents accumulation of grease deposits, dirt and other residues, having regard to their use.

b. A food contact surface such as a cutting board used for raw food and ready-to-eat food should be cleaned and disinfected between each use. If an equipment or an utensil is used continuously at room temperature for handling high risk foods (e.g. meat slicers), it should be cleaned and disinfected at least once every 4 hours.

c. Any part of a thermometer, especially the temperature probe that will be inserted into the food for temperature measurement, should be cleaned and disinfected between use.

d. Non-food contact surfaces should be cleaned at a frequency that prevents accumulation of dirt, grease and other residues, preferably once a week or more as required.

e. Cleaning has to be carried out in a systematic manner, for example, in sequence from walls, non-food contact surfaces of equipment such as cupboards, refrigerators, cooking ranges and then the floors.

\subsubsection{Cleaning Facilities}

Food establishments should have adequate facilities to enable effective cleaning activities. There should be separate cleaning rooms with proper segregation between cleaned and unclean equipment such that cross-contamination is prevented.

\section{Rationale:}

Accumulation of food waste, dirt and grease, etc. provides food for pests and enables microbial growth, which are conducive to food contamination. This dirt and waste may come from a variety of sources including 
food spills, food handlers' shoes, linens and food packaging, etc. brought into the premises. Accumulation of liquid on floors could provide a water source for pests and encourage their presence in the premises. It could also be a source of microbial contamination. Cracks, crevices or similar defects on walls, floors or ceilings can harbour pests or become their breeding grounds. Effective, frequent and regular cleaning, disinfection/ sanitising, and maintenance of floors, walls, ceilings and equipment are thus necessary for removal of food contaminants and prevention of microbial proliferation.

\subsubsection{Cleaning and Disinfection Process}

a. Cleaning and disinfection of equipment and utensils should be done as separate processes. A food contact surface needs to be thoroughly cleaned before it is disinfected

b. After cleaning, food contact surfaces of equipment and utensils shall be:

i disinfected to a temperature of $82^{\circ} \mathrm{C}$ or equivalent in a dish washing machine;

ii disinfected by immersing in a non-toxic solution containing a disinfecting agent of a type approved by the Food Control Department; or

iii disinfected using any other method that can reduce the microorganisms to a level which is neither harmful to health nor the quality and safety of foods.

c. All cleaned and disinfected equipment and utensils should be thoroughly rinsed and dried by evaporation (air dry);

d. Cleaned and disinfected equipment should be stored in a place and manner that prevents contamination;

e. Adequate care must be taken to ensure that water, debris and other materials are not spread to clean areas when high pressure jets are used;

f. In retail food service establishments:

i separate sinks should be provided for food preparation and equipment washing depending on the size and extent of activities;

ii all dish-washing activities should be done in sinks within the food premises;

iii wash-up sinks should be cleaned at a frequency that prevents accumulation of grease deposits and other residues;

iv sinks used for the purpose of washing ready-to-eat foods should be cleaned and disinfected before use;

$\mathrm{v}$ wash-up sinks should not be used for miscellaneous articles;

vi hand washing should not be carried out in sinks that are used for other purposes. Sinks should be identified in some ways that they are used for such purpose only, e.g. by putting up a notice such as "For washing food or utensils only" or "Not to be used for hand washing" etc. 
Rationale:

Cleaning is a process for the removal of contaminants such as food residues, dirt, grease and bacterial film from a surface, which is achieved by the use of water and proper detergent. Utensils and equipment should be disinfected, either mechanical or manually, after cleaning to minimise the risk of food becoming contaminated with micro-organisms when coming into contact with the utensils or equipment.

A bactericidal agent or disinfectant should be applied at the proper concentration, temperature and for the appropriate length of time to achieve desirable reduction in bacterial level, whose effectiveness is a function of the time and temperature that the utensils and equipment to be disinfected are exposed to.

Disinfected equipment and utensils shall be handled in a sanitary manner after disinfection and should be allowed to dry as quickly as possible as most micro-organisms cannot survive in the absence of water. Drying by towels or storing on a dirty surface may lead to re-contamination of cleaned and disinfected surface.

\subsubsection{Cleaning Chemicals}

a. Chemicals used for cleaning and disinfection/sanitising must be suitable for use in food establishments and be approved by the relevant department of Dubai Municipality. The establishment should determine the appropriate cleaning method in consultation with the supplier of chemical service provider.

b. Detergents used for cleaning food contact surfaces should be appropriate for the task, and be able to effectively remove food residues on equipment and utensils.

c. Material Safety Data Sheet (MSDS) along with the documents of validation pertaining to the suitability and effectiveness of the chemical and/or the process of disinfection/sanitising should be retained in the food establishment at all times.

d. The documents should include validation data with the following details:

i evidence that the chemicals are suitable for the tasks being carried out;

ii evidence that the chemicals will be effective against pathogens of concern;

iii evidence that the chemical is suitable for use in food establishments.

e. Effectiveness of the cleaning method should be evaluated by the food establishment and appropriate data should be gathered to validate the method selected and to make adjustments as needed.

f. Instructions on how to use the agents should always be followed, especially the optimal combination of the temperature, $\mathrm{pH}$ and concentration of the agent. If the instructions are not clear, further advice should be sought from the supplier.

g. All chemicals should be labelled properly and never decanted into food containers

h. Chemicals should be stored securely and in accordance with the manufacturer's recommendation.

i. The concerned person in the establishment should:

i be trained on the use of the disinfectant;

ii check the temperatures of the water and the disinfectant concentration frequently to ensure that effective results are occurring. Test kits/strips should be obtained from the supplier and stored for convenient use near the dishwasher;

iii keep records of disinfectant concentrations. 


\subsubsection{Cleaning Tools and Equipment}

The design of the cleaning tools and their handling and storage are also important to ensure effective cleaning.

a. The design of the cleaning tools must be suitable for effective cleaning with no hiding places for food residues or bacteria to accumulate.

b. Materials should be suitable to withstand the effect of cleaning chemicals.

c. Brushes made of wood and natural bristles must be avoided and worn out brushes must be replaced.

d. Mops with detachable heads that can be washed should be used for cleaning the floor.

e. When high risk food production areas are very close to potentially contaminated raw food areas such as butchery, produce cleaning area etc., tools should be colour coded to restrict the use of tools of a certain colour to a specific area.

f. Cleaning tools should be stored clean and dry after use in designated areas that facilitates drying.

g. Equipment and mechanical aids such as floor scrubbers and rotating washers should be carefully chosen so that it is suitable for the use intended.

\subsubsection{Cleaning and Disinfection Programme}

a. To achieve the appropriate standard of cleanliness, all food establishments should develop a cleaning / disinfection programme that encompasses all equipment and facilities as well as general environmental cleaning. Cleaning methods need to be developed that are suitable for the item/ equipment/surface to be cleaned and should describe both the method and frequency of cleaning specific areas.

b. Food establishments should conduct an evaluation for each area to decide the cleaning method. Consideration should be given to potential microbiological risks, i.e. pathogenic and spoilage microorganisms, and potential chemical and allergen risks.

c. Cleaning programme should be maintained with the due consideration to the following details:

i the size, type and temperature of area to be cleaned, the structure of the building and the wall, floor and ceiling finishes and the type of material it is constructed of;

ii the type of soiling and water hardness, water pressure and drainage system;

iii if cleaning is necessary during food preparation, adequate measures to remove or protect food;

iv measures to reduce the risk of spreading contamination, especially when using high pressure jets;

d. Food establishments should maintain a written cleaning programme that specifies:

i what is to be cleaned;

ii chemicals, materials and equipment to be used for cleaning;

iii dilution and contact time of the chemical;

iv method of cleaning ( how);

$\mathrm{v}$ frequency of cleaning (when and how often); 
vi time necessary to clean it;

vii who has to clean it (name of the person);

viii safety precaution to be taken- protective clothing to be worn;

ix who is responsible for monitoring and recording what has been cleaned.

Rationale:

The requirement for a written disinfection programme is very similar to the requirement, in this Code, for management principles to control food hazards. The objective of the disinfection programme is to provide reasonable assurance that the food premises is being cleaned and disinfected effectively and consistently. While the detailed programme described above may do this, the costs of such a detailed programme in necessary time and resources should be balanced by the benefits. As well, particularly in a smaller food premises with simple operations, the cleaning and disinfection may be made up of only a few relatively simple steps. The complexity of the required written sanitation programme should reflect the complexity of the cleaning and disinfection of the operation.

\subsection{Pest Control}

a. Food premises should be kept free of pests like rodents, insects, birds and animals.

b. Food premises and surrounding areas should be inspected regularly to look for signs of pest infestation.

c. Whenever pests are detected, control actions should be taken promptly to rectify the situation.

d. Pest control activities shall be done by specialist licensed pest control agencies that can carry out pest inspection and subsequent control work. They must only use approved chemicals and methods.

\section{Rationale:}

Food premises are easily infested by pests because they provide them with ample food sources and numerous harbourage places. A pest infestation in a food premises can result in food becoming contaminated by foreign matter (e.g., insect parts, rodent hair, etc.), pest urine/faeces, and/or pathogenic microbes carried by pests. Improper handling of food and food debris, accumulation of disused articles and presence of structural defects render food premises highly susceptible to pest infestations.

Pests will not only pose food safety problems but also transmit diseases to human. They can carry pathogenic organisms to foods physically by their bodies, hair and excreta.

\subsection{Prevention and Control of Pest Infestation}

To avoid pest infestation in the premises, it is necessary to maintain food establishment at high standards of hygiene and immediately fix any structural defects. Proofing measures should be adopted to block the entry of pests. Foods should be properly protected and waste disposed of to remove their food source. 
a. Prevention of Entry of Pests

Particular attention should be given to the following in the prevention and control of pests in food premises:

i Any holes or crevices in ceilings, walls and floors should be sealed by cement or metal plates ;

ii Threshold clearance of doors should be lowered to not more than $6 \mathrm{~mm}$ and metal kicking plates should be affixed at the lower edges of doors and door-frames to prevent entry of rats and mice;

iii Windows, ventilation openings and doors should be installed with mesh screens. Doors / screen doors should be self-closing and kept closed at all times;

iv Any missing or damaged gratings of drains should be installed or replaced immediately.

b. Elimination of harbourage for pests

i False ceilings should be avoided in food preparation or storage areas as far as possible;

ii Any defects on walls, floors, ceilings, woodwork and all other parts of the structure of food premises should be promptly repaired;

iii Disused articles or equipment should not be stored in food premises. If storage is unavoidable, they should be moved regularly to eliminate harbourage of pests.

c. Elimination of food sources to pests

i All foods as well as condiments should be covered and stored properly in sealed containers;

ii Floors of food premises should be kept clean and free from food remnants, especially overnight Preparing food or cleaning utensils is strictly prohibited in the yard or the rear / side lanes;

iii Refuse should be stored in refuse containers with well-fitting covers. Refuse bags should be tied up before disposal to prevent spilling and attraction of pests. They should be cleared at least once a day, preferably every night to avoid leaving refuse overnight.

d. Eradication of pests

i Places, clothing and equipment contaminated by pests should be cleaned and disinfected as soon as possible;

ii Pest control devices should be designed and located to effectively control the presence of pests in a food premises. Insect control devices designed to trap insects by adhesive or devices that may expel the insects or insect fragments should be installed so that the dead insects or insect fragments cannot fall onto exposed food or equipment. To be effective, insect traps (sticky pads or similar devices) should be changed regularly or when loaded with insects;

iii Electric Fly Killers (EFKs) equipped with catch trays can be used to eliminate flying insects in food premises. The EFK should be placed at least $1.5 \mathrm{~m}$ (preferably $4.5-6 \mathrm{M}$ ) away from a food handling area. Only low wall or ceiling mounted type EFKs should be used, and EFKs should not be directly above food preparation or storage areas;

iv Pest control activities shall be done by specialist pest control agencies licensed and approved by the concerned Department to operate in Dubai, utilising approved chemicals and methods. The food establishment has the primary responsibility to ensure that a competent person carries out the pest control operation in the premises; 
$\mathrm{v}$ Rodenticides and insecticides should be applied in such a manner as not to contaminate foods - they should not be applied while food production / preparation is taking place, and all open foods should be well covered and protected. Where, due to the nature of the food operation (e.g., 24-hour restaurants) this cannot be adhered to, reliance on physical control methods are preferred to the use of chemicals - especially sprays. Open food should be protected from contamination;

vi In the event of pest infestation, any contaminated equipment, utensils and food contact surfaces should be thoroughly cleaned and disinfected. Any food that has been contaminated by pests or pest control chemicals should be disposed off.

e. Keeping of Records

i Management of food establishment should keep proper records of pest control inspections, surveys, maintenance and service, etc. in respect of their establishment. Owners/operators should take note of information the pest control technician may need for follow-up.

ii Documentation should include:

- copy of the contract with the pest control agency

- the name of the pest control technician responsible

- the chemicals used for pest control (with the concentrations applied),

- the procedures and methods used

- the frequency of application; and

- records of inspection and monitoring.

\section{Rationale:}

Presence of pests increases the likelihood of contamination of food and may cause significant damage to food establishment. Properly designed and installed pest control devices can be used as a means of eliminating pests.

To ensure that pests are properly, effectively and safely eradicated, the Person in Charge should rely on approved pest control agencies and emphasise integrated pest management practices that minimise the reliance on chemical controls (if pest control measures require the application of chemicals). Since chemicals used to eradicate pests may also be toxic to humans, food should be adequately protected while these substances are being applied in the food establishment. Food establishments which have become infested should be thoroughly cleaned to eliminate pest harbourage. Surfaces contaminated by pests should be cleaned and disinfected to destroy microbial pathogens which might be present and which might contaminate foods.

The first and best line of defence is to prevent entry of pests by proper inspection and maintenance of the premises. The second line of defence is to deprive pests of food source by proper storage of food and prompt removal of refuse, food remnants and spills.

To verify that appropriate pest control measures have been undertaken, all aspects of pest control operations shall be documented and monitored. 


\subsection{Use of Chemicals and Toxic Substances}

a. Chemicals, cleaning and disinfecting compounds and other toxic substances kept in a food establishment shall be:

i used in compliance with the manufacturer's labelling, directions or specifications and approved by the Food Control Department;

ii used only in such a manner and under such conditions that the substances do not contaminate food, equipment and food contact surfaces, or cause a health hazard.

b. The chemicals, cleaning and disinfecting compounds and other toxic substances shall be stored:

i in a compartment separate from food, food contact surfaces and utensils;

ii in clearly labelled, non-food containers, which are (where appropriate) lockable.

\section{Rationale:}

Special care should be taken when handling dangerous or toxic substances in food premises. They should be used according to manufacturer's specifications, not only to ensure they function as intended but also to ensure worker safety.

To prevent the adulteration of food products, dangerous or toxic chemicals shall be kept in containers which are clearly labelled to identify the contents, and stored in areas separate from food and food equipment. Locked containers or storage facilities can prevent malicious or accidental contamination of food. 


\section{Personal Hygiene}

\subsection{Personal Health and Illnesses}

a. High standards of personal hygiene should be maintained in all food establishments to ensure that those who come into contact with food are not likely to contaminate food by:

- maintaining an appropriate degree of personal cleanliness;

- behaving and operating in an appropriate manner.

b. All food handlers should be in good health, have good eyesight and be able to read, especially if they are responsible for checking thermometers, instructions on labels, date coding etc.

c. Food handlers should undergo medical fitness tests conducted by the concerned government authority and retain relevant occupational health cards indicating such.

d. All staff engaged in food handling must:

i be free from any symptoms of illnesses or communicable diseases such as diarrhoea, vomiting, fever, sore throat, abdominal pain and jaundice;

ii not be carriers of food-borne diseases e.g. typhoid/paratyphoid, cholera, hepatitis type A; and

iii not be suffering from discharging wounds or sores on any exposed part of their bodies; or from discharge from their ears, eyes or noses.

e. A food handler should be instructed in writing to report to the person in charge if they are suffering from a communicable disease in the following situations:

i they have any symptoms associated with an acute gastro-intestinal illness, such as diarrhoea, fever, vomiting;

ii they are suspected of causing or being exposed to a confirmed communicable disease outbreak; or,

iii they live in the same household as a person who is diagnosed with a communicable disease.

f. If a food handler is suffering from an illness or communicable disease, the Person in Charge is responsible for ensuring appropriate action is taken. This may include excluding the individual from activities that involve the handling of food or food contact surfaces, food utensils and equipment, or authorising the individual's absence from the work place.

g. When returning to work after medical leave or illness, food handlers should have written clearance from the treating physician, particularly in the case of diagnosed, reportable communicable diseases.

h. Food handlers suffering from any food borne illness should not return to work until 48 hours after the disease symptoms have completely cleared and they have finished using any medication.

\subsection{Injuries}

a. Food handlers with open infected lesions, cuts wounds on their bodies must not be allowed to handle food or to come into contact with food utensils, equipment and food contact surfaces.

b. Food handlers with clean cuts / wounds can work if the cuts are completely protected by brightly coloured, waterproof dressings that can be spotted easily if fallen in to the food. 
Rationale:

Several types of communicable diseases can be transmitted by consumption of food. Food handlers should eliminate the opportunity for pathogenic micro-organisms being transferred to food and spread to consumers.

Food handlers can carry communicable diseases, especially if they themselves have been infected or are in contact with persons or objects that may carry the harmful microbes of those diseases. Consequently, food handlers may spread these diseases throughout the food premises if they do not maintain an appropriate level of personal hygiene and avoid habits that may contaminate food.

Some food poisoning bacteria are commonly found on open wounds or cuts of their bodies. Illnesses may be spread to consumers if food handlers suffering from illnesses or with open wounds are allowed to take part in food activities.

\subsection{Personal Hygiene Practices}

a. Food handlers should maintain high levels of personal hygiene at all times.

b. In the course of handling food and for any person entering a food preparation or storage area, hair should be covered with a clean hat or hair net. Where required, beards should be completely covered with beard nets.

c. While in food handling area, food handlers should not wear watches, or jewellery which may easily become detached (e.g. earrings).

d. Only clean and preferably light coloured outer clothing or protective overalls should be worn by food handlers. If they become soiled during food preparation, they should be changed or cleaned as necessary. Food handlers should have at least 4 sets of uniforms to ensure that they can change to clean uniforms when necessary.

e. Hand hygiene is an important step to prevent spread of foodborne illnesses.

i Hands of food handlers should be kept clean at all times. Nails should be kept short and free of nail varnish

ii Food handlers shall wash their hands-

- before commencing work

- before handling food

- after visiting the toilet

- after putting on or changing a wound dressing

- after dealing with an ill colleague or customer

- after coming into contact with pests or their faeces

- after handling contaminated raw foods of animal or plant origin

- after handling soiled equipment or utensils

- after coughing, sneezing, smoking, eating, drinking or blowing nose 
- after handling animals or waste

- after engaging in any activities that may contaminate hands (e.g. handling money, carrying out cleaning duties, etc.); or

- after returning from a break.

iii hand washing must be frequent, thorough and performed in wash hand basins;

iv wearing gloves should not be an alternative to proper handwashing.

\subsection{Personal Habits}

a. Inside food preparation areas, food handlers should refrain from performing the following behaviours/habits which may result in contamination of food:

i smoking or using tobacco and spitting;

ii chewing, eating, sneezing or coughing over unprotected food or food contact surfaces;

iii touching ready-to-eat food with bare hands;

iv sitting, lying or standing on any surface liable to come into contact with food;

$\mathrm{v}$ tasting food with fingers; and;

vi touching hair or other parts of bodies such as noses, eyes or ears

vii dining inside food preparation area.

Rationale:

Pathogens are commonly found on the skin and in the noses of healthy people. Scratching the head and nose can result in bacteria being transferred by hands onto food, which may cause illnesses to customers. Smoking in food rooms may cause food contamination by cigarette ends, ash or hands.

Prevention of foodborne illnesses should begin with good personal hygiene practices by food handlers in both personal cleanliness and habits to prevent contamination of food by pathogens.

\subsection{Visitors}

Any visitor to a food preparation area should be appropriately dressed and should observe the same hygiene as food handlers, including hand washing and hair restraint policies. They should refrain from coming into proximity or contact with food and food equipment, and from any activities that could contaminate food. 


\section{Training of Food Handlers}

\subsection{Role of the Person in Charge}

The Person in Charge in a food establishment should ensure that all food handlers are trained to a level of food hygiene training appropriate to the type of work they undertake. After successful completion of the formal training programme, the food handlers should be competent and capable of demonstrating the skills at work.

\subsection{Training programme}

Food establishments should maintain a documented training plan for all employees based on their training needs. Training programme should be based on the level of food safety risk in the food premises, as listed below.

a. All food handlers must be formally trained on food safety. Where necessary, staff who are not directly involved in food preparation, but are involved in managing food related services (such as a person handling the buffet counter, food delivery etc.), should also be formally trained.

b. Food handlers should be trained in food safety to a level appropriate to the job they perform. Such trainings should also be based on the level of food safety risk in the food establishment. Factors for assessing the level of food safety risk include:

i the nature of food produced or manufactured in the establishment;

ii the manner in which food is handled or served;

iii the type of menu items or the complexity of the processes used (i.e., prepared-from-scratch menu items versus preparation or reheating of pre-packaged, ready-to-eat foods; and

iv the number of meals served daily, the size of establishment, and the type of customers the food is catered to (i.e., higher risk populations).

c. Formal food safety training should be obtained from a trainer approved by the Department.

d. The management of food establishment should promote food safety training to employers/ food handlers by conducting on-going in-house courses for them or arranging them to participate in courses.

e. Periodic assessment of the effectiveness of training and instruction programme should be made by the PIC.

f. The PIC must maintain records indicating those employees who have been trained and their relevant particulars.

\subsection{Continuing Educational Training}

a. Every food establishment should promote food safety education through ongoing training, which may include additional classroom instruction, on-the-job training, food safety certification from a recognised programme of instruction, seminars, and employee meetings.

b. Food handlers should participate in a refresher or updating course after one year of training or, shall be retrained if deterioration in food handling practices is noticed.

c. The PIC shall provide evidence of continuous learning and refresher training appropriate to the level of food safety risk in the business. 
Rationale:

Studies have demonstrated that the quality of food handling techniques improves for the six months following a formalised training programme. However, after that period, food handling practices can deteriorate to pre-education levels. It is recognised that inspections by a regulatory authority or by an internal inspecting body can help alleviate the problem, by re-emphasising the principles of good food handling practices.

However, food safety is too important to rely solely upon monitoring and auditing conducted by the regulatory authority. The food industry should take responsibility for adequately preparing food handlers to fulfil their job requirements, and to significantly contribute to a safe food industry. 


\section{Provisions Applicable to Sale, Import and Export of Food}

\subsection{Registration and Approvals}

a. Prior to importing or exporting food, food establishment shall register in:

i Dubai Municipality's e-Government system;

ii Food Import and Re-export System (FIRS) of the Food Control Department.

b. Prior to the importation of any food item, the food establishment should ensure that labelling on the food item is approved using FIRS.

c. All imported or re-exported food items should be individually registered in the FIRS System.

\subsection{Sourcing Food}

a. Food establishments must ensure that food and materials that come in contact with food imported to Dubai are:

i obtained or procured from sources that are regulated by the relevant food authority at the country of origin;

ii produced under sanitary conditions in an establishment regulated by the relevant food authority at the country of origin.

b. Food and food contact materials imported to Dubai must comply with the UAE standards, especially those pertaining to labelling, shelf life, and the relevant requirements of this Code and associated guidelines.

\subsection{Food Inspection and Document Verification}

All imported food products and food contact materials are inspected by the Food Control Department at the port of entry. Authorised officers verify the document and collect samples for laboratory analysis when necessary to ensure their compliance to relevant standards and regulations.

a. At the port of entry, importers of food must submit the Health Certificates for each consignment of food that clearly state:

i the quantities and description of imported food items;

ii that the imported products are produced or manufactured according to the requirements of Dubai Municipality in an establishment that is licensed and supervised by the competent food authority at the country of origin.

b. Consignments of raw meat and poultry shall be accompanied with Halal Slaughtering Certificates. Halal Slaughtering Certificates are valid only if they are issued at the country of origin by an Islamic Society approved by the Government of UAE.

c. Halal Certificates are required for the following products:

i all processed meat products produced from animals that are Halal;

ii foods that contain meat or poultry products or ingredients of animal origin (e.g.. gelatin) with the exception of seafood. 
d. The food establishment should ensure that additional requirements and supporting documents and / or laboratory analytical reports may be required for the import of specific food products when applying for import permit.

e. Food contact materials should be accompanied by certificates issued by a competent laboratory indicating that the materials are food grade.

Further information is provided in the 2013 edition of the Guideline "Import and Re-Export Requirements for Foodstuffs" issued by the Food Control Department.

Rationale:

Operators of food establishments should ensure that all the information pertaining to a food product is collected prior to importation. The information should include the nature and type of the product, handling requirements, shelf life, labelling etc. This information will help the importer to prepare the necessary documents that have to presented at the port of entry.

Prior approval of the labels through the FIRS will help to make necessary changes in the label if required. This will be useful to eliminate unnecessary delay in the release of the consignment or even avoid possible rejection in the case of a serious violation of the requirements. 


\section{Miscellaneous}

\subsection{Food Labelling}

a. Food establishments should not import, sell, consign or deliver any pre-packed food item if the package on the food does not bear a label containing all the information required by Food Control Department.

b. Unless otherwise exempted by the Department, the package should bear a label that is printed on or securely attached in a prominent and conspicuous position to the package, containing such particulars, statements, the required information in Arabic.

c. Pictorial, or other descriptive matter appearing on or attached to, or supplied along with or displayed on the food or the packaging of the food, shall not include any false or misleading statement, word, brand, picture, or mark purporting to indicate the nature, stability, quantity, strength, purity, composition, weight, origin, age, effects, or proportion of the food or any ingredients thereof.

d. Illegal or unauthorised nomenclature, terminology, coding, pictorial shall not be used on the packaging. This includes but are not limited to:

i any words, expressions, or pictures which are offensive to any religion or to any religious symbols;

ii any photos, pictures, expression or words which imply any immoral impressions

iii any words or expressions which are offensive to the traditions and values of the country or its symbols;

iv religious symbols.

e. Commercially manufactured pre-packaged food items sold as individual units should bear or have embossed or impressed on the label or elsewhere of the package, a date mark with the production and expiration dates, in the manner specified and approved by the Food Control Department.

f. Date marking on the original packaging should not be removed, erased, altered, obscured, superimposed or in any way tampered with.

g. Where the validity of the date mark of any pre-packaged food is dependent on its storage, the storage requirement of that food should also be stated on its label or package.

h. In food service establishments, refrigerated ready-to-eat high risk foods, prepared and held for more than 6 hours, should be marked with the expiration time or date.

i. Where necessary, instructions for use after opening the original packaging should be provided. E.g. Store chilled after opening and consume within three days.

j. For those pre-packaged foods that are intended to be eaten cooked, the following requirements apply:

i instructions for use are required on the food label when it would be impossible to make appropriate use of the food in the absence of such instructions;

ii instructions for use should be indicated in such a way as to enable appropriate use to be made thereof. E.g. where cooking is required then cooking instructions must be provided. If the product is frozen, the cooking instructions should indicate if cooking should be from frozen or thawed prior to cooking; 
iii where cooking or reheating instructions are included, they should be validated by the producer or manufacturer to ensure the pathogen(s) of concern will be destroyed and the product is safe to consume. This validation study should take into consideration whether the products will be cooked/reheated from frozen or thawed prior to cooking. These instructions, e.g. cook from frozen or thaw prior to consumption should also be included on the label.

\subsection{Product Shelf Life}

a. The food establishment is responsible for determining the shelf-life of food products under defined conditions, which should take into account reasonably foreseen conditions of distribution, storage and use.

b. For those products for which the shelf-life is mandated by the Food Control Department, the shelflife should not exceed the time specified by the Department.

c. In food service establishments such as restaurants, shelf-life of high risk or perishable foods prepared as per the process outlined in section 3 of this Code do not require validation if stored for three days or less. However, food establishments should, as a part of the review of the food safety program, periodically verify the effectiveness of control measures and the stability and suitability of the product during the shelf-life.

d. Food manufacturers, and establishments such as bakeries, catering companies and departmental stores that prepare and distribute pre-packaged high risk or perishable foods should validate the shelf-life and obtain shelf life approval from the Food Control Department prior to the label approval process.

e. While determining the shelf life, the food establishment should take account of the following:

i controls on suppliers assuring raw material quality;

ii analysis of trends in results of microbiological testing of raw materials and final products;

iii analysis of trends in results of microbiological testing of the process environment and equipment;

iv hygiene controls applied in the process environment;

v well established industry standards;

vi rate of microbiological spoilage and maintenance of organoleptic quality under foreseen conditions of storage and use.

g. Pre-packaged foods that are prone to rapid deterioration after the original packaging is removed (such as canned foods, juice bottles etc.) should be used as per the recommendation of the manufacturer.

h. Shelf life of raw cereals, pulses and dry foods depend on the raw materials, storage and handling. Such products are exempted from the requirement for validation. However, such foods should be handled and stored in a appropriate manner.

Note: Validation study should take into consideration the intrinsic and extrinsic properties of the product that affect shelf-life. Intrinsic properties are those properties that are an inherent part of the food product such as $\mathrm{pH}$ and water activity. Extrinsic properties are the properties of the environment in which the food is stored such as temperature and atmosphere. 
Rationale:

No food can be kept indefinitely. In the case of high risk products, shelf life could have a significant impact on the safety of the product. Product shelf lives should be established by taking into account of the production environment, packaging and storage conditions, and the handling of the product.

The identification of the pathogens associated with raw materials and the production environment is critical for the accurate determination of a safe shelf-life. It is important to note that deviations from normal conditions, such as high levels of initial contamination in raw materials or elevated temperatures during storage or transport will impact on the safety of the product during its shelf-life.

\subsection{Product Menu in Food Service Establishments}

a. Food service establishments such as restaurants and cafeteria shall have product menu printed both in Arabic and English. Foods with allergens or Non-Halal ingredients shall be clearly identified in the menu.

b. Food service establishments such as restaurants and cafeteria shall provide all information about the product when requested by the customer.

\subsection{Filtration and Disinfection Facilities for Fish Tank Water}

a. Water used for keeping marine live fish or shellfish intended for human consumption should be filtered and disinfected by filtration and disinfection facilities. These facilities should be maintained in good working order at all times.

b. The filtration / disinfection system should be a closed loop system capable of providing continuous filtration and disinfection action.

c. Dedicated staff should be assigned to take care of the cleaning and maintenance of the whole system.

d. Fish tank water should be changed regularly to remove harmful substances produced by the stock after a period of time.

\subsection{Single-Use Items}

When using single-use items (non-reusable) such as instrument, apparatus, utensil or any other such thing for handling of food, such as drinking straws, disposable eating and drinking utensils, disposable food containers and disposable gloves, etc.;

a. Such items should be properly protected from risk of contamination by storing inside dust and pest proof containers or cupboards until they are used, and should be discarded if they are contaminated. They should not be re-used for any other purpose that will make them come into contact with any food or the mouth of a person;

b. If gloves are used for handling food,

i hands must be washed properly before wearing gloves;

ii only disposable gloves shall be used, which shall be used for only one task, e.g. for either handling ready-to-eat food or raw food, and for no other purpose; 
iii the same disposable gloves should never be used to handle raw food and then ready-to-eat food;

iv they should be discarded if damaged, soiled, or when interruptions occur in the operation.

Note: Gloves are not an alternative for proper handwashing.

Rationale:

Single-use items are not manufactured to permit effective cleaning and disinfecting. If these items are reused, food coming into contact with these items may become contaminated. Use of the same disposable gloves for handling raw and ready-to-eat food easily leads to cross-contamination.

\subsection{Prohibition of Animals}

Live birds, pets or animals, such as dogs and cats, except live seafood are not allowed to be kept or present in food service establishments and in food establishments that are not legally authorised to handle such animals or birds.

\subsection{Procedures for Handling Non-Halal Food}

Halal is an Arabic word meaning "allowed" or "lawful". Muslims are permitted to consume only Halal food. Food is considered Halal if it does not comprise of Haram (prohibited) items, or is not contaminated with Haram items, or if it is not prepared as prescribed.

Refer to the Halal Food Guidelines of Dubai Municipality for further information.

\subsubsection{Requirements for Imports, Purchase and Sale of Non-Halal Food}

a. Non-Halal products shall not be imported, exported, processed or sold without obtaining a prior permit from the Food Control Department.

b. The food label on packaged Non-Halal products shall clearly and visibly state the ingredients in Arabic and English Languages. The label shall state clearly that it is a Non-Halal product.

c. Non-Halal products shall not be mixed with Halal foods or other foods intended for consumption by Muslims during transportation, storage, preparation, or display.

d. The importer/trader has the primary responsibility to ensure that Halal products or other foods are not mixed with Non-Halal products or any other doubtful ingredients.

e. The importer/trader should ensure that Non-Halal Products are sold ONLY to food establishments that have prior permit for the sale of Non-Halal foods.

\subsubsection{Requirements for Storage of Non-Halal Food}

a. Refrigerated and frozen Non-Halal food shall be stored in designated refrigerators or freezers.

b. Non-Halal products shall be stored in separate, cabinets, bins, and storage vessels to prevent contamination with other food. 
c. Items that are dry shall be stored in sealed containers. Liquids or wet items should be stored in leak proof containers, which prevent other liquids from accidentally mixing with them.

d. Containers shall be clearly labelled to prevent confusion or contamination. For example in the case of pork products, it is preferable to have the items colour Coded and marked "pork."

\subsubsection{Requirements for Preparation of Non-Halal Food}

a. A complete physical separation shall be provided for the area where Non-Halal foods are displayed or sold.

b. Non-Halal foods shall not come into contact with surfaces of utensils and equipment that are used for other food products.

c. The equipments and utensils shall be designated for Non-Halal foods preparation and no other meals should be prepared on this equipment.

d. Separate, colour coded cutting boards and knives shall be used for Non Halal foods .

e. Non-Halal foods products shall be cooked on/in designated ovens .

f. Warmers for Non-Halal foods shall not be used for other foods.

g. Plates, utensils and equipments used for Non Halal foods shall be washed separately, preferably in a separate dish-washing machine. It is advisable to use disposable plates if possible.

h. Access to Non-Halal foods preparation area shall be restricted, as much as practically possible, to designated food handlers.

i Food handlers can contaminate food in a number of ways, food handlers shall not handle Non-Halal and Halal food items at the same time. Hands shall be thoroughly washed before working or touching other food items or ingredients.

j. Non-Halal foods shall not be prepared nor stored in areas that are designated for other products.

k. Where pork products are handled, a sign board shall be placed in both English and Arabic language stating 'Pork products only' The signage should be clearly visible to food handlers.

\subsubsection{Serving Non Halal Foods in Restaurants}

a. Food business operator has the primary responsibility to inform the customer that the restaurant serves Non-Halal foods. Menu card shall indicate this clearly on the first page.

b. Menu card in restaurants shall clearly identify any product that has Non-Halal foods. Such food items should not be put along with names of other foods.

c. Any food that contains Non-Halal foods shall not be served along with other food. Separate serving utensils and equipments should be used.

d. In buffet, area that serves Non-Halal foods shall be clearly separated from other areas.

e. In display, all products shall be clearly labelled in Arabic and English.

Note: Preparation of pork is allowed in 5 Star hotels and Clubs with prior approval. 


\subsubsection{Sale of Pork Products}

a. A departmental store or supermarket will be allowed to display and sell pork products after prior approval from the food control department of Dubai Municipality.

b. Pork products can be sold in a departmental store or supermarket with an area not less than 2500 square feet.

c. Space provided for pork products should be adequate and based on the extent of activity.

d. Preparation and storage facilities shall be provided as per the requirements mentioned in the Code.

e. If there is butchery for handling pork products, it shall be separate and equipped with all necessary supplies.

f. Departmental stores and Supermarkets must have a designated person to handle pork products, and a separate cash counter to sell such products.

g. The authorised officer from Food Control Department shall verify the layout of the store or the supermarket and provide the approval if the establishment satisfactorily meets all the requirements.

\subsection{Product Traceability and Recall}

a. A system to ensure traceability of food and any other substance intended to be or expected to be incorporated into a food should be established at all stages of food importation, production, processing and distribution.

b. All food items imported, sold, consigned or delivered in to the Emirate of Dubai must be registered with the Food Control Department.

c. Food establishments shall be able to identify any person/establishment that has supplied them with, or any substance intended to be, or expected to be, incorporated into food or packaging material. To this end, establishments should have in place documented systems and procedures which allow for this information to be made available to the Food Control Department if required.

d. Food manufacturers should have a system to identify and trace product lots and follow this through all raw materials (including ingredients, all types of packaging materials and processing aids), all stages of processing and distribution of the finished product to the customers in a timely manner.

e. Food establishments shall have in place documented systems and procedures to identify businesses to which their products have been supplied. This information should be made available to the Food Control Department when required.

f. Food which is placed on the market or is likely to be placed on the market in the community shall be adequately labelled or identified to facilitate its traceability, through relevant documentation or information in accordance with these regulations.

g. Food manufacturers, importers and distributors shall promptly withdraw or recall food products they import, produce or distribute to other establishments if such foods are found to be unacceptable, unsafe or adulterated, or do not conform to the Islamic law or the traditions and norms in the United Arab Emirates.

h. Food manufacturers, importers and distributors shall promptly recall foods if the Food Control Department or other concerned authorities issue a memorandum or a decree to recall specific food form Dubai markets. 
i Food establishments should notify the Food Control Department in the event of a withdrawal or a recall. Consumers should be notified if the product has entered the market and has reached the consumers.

\subsection{Customer Complaint Handling}

a. The food establishment should have a customer complaint handling system that gives guidance on how to respond, investigate and take preventive action when there is a food related complaint.

b. All food related complaints which include product related complaints and complaints pertaining to suspected foodborne illnesses should be logged in the complaints record.

c. Complaints must be investigated promptly and efficiently, and the details of investigation and corrective action must be retained for a period of at least one year.

d. Food establishment operator must contact the Food Control Department immediately if:

i an outbreak of foodborne disease is suspected;

ii if the complainant is injured or critically ill.

Note: A foodborne-disease outbreak is defined as an incident in which two or more persons experience a similar illness resulting from the ingestion of a common food.

\subsection{Power Outage}

Appropriate decision making before, during and immediately after a power outage is necessary to ensure food safety. It is recommended that food establishments develop a power outage plan before the need arises. The following are recommendations that apply to food safety during an extended power outage:

a. High risk and perishable foods, if subject to a temperature of more than $5^{\circ} \mathrm{C}$ for more than 2 hours, should be discarded.

b. Frozen foods should be discarded or used immediately if there are any signs of thawing.

c. Preparation and cooking activities must be discontinued until the time power is restored. Partially cooked foods should be discarded.

Note: Do not open the doors of chillers and freezers unnecessarily during a power outage. Food establishments should also refrain from putting hot foods into the chiller or freezer as this will raise the temperature of the food inside the equipment.

\subsection{Use of Wood in Food Premises}

a. Hard maple or an equivalently hard, close-grained wood may be used for cutting boards, cutting blocks, bakers' tables; and utensils such as rolling pins, doughnut dowels, salad bowls, and chopsticks. Such equipment should be suitable for contact with food, disinfection, and be maintained well.

b. Wooden pallets should be handled and stored in a way that it poses no threat to the safety of the food. When wooden pallets are used: 
i the food safety programme should include a 'wood use policy' that clearly states where wooden pallets will be used;

ii an effective documented verification practice must be in place to ensure that the pallets are clean and free of damage and pests.

Note: Both wooden and plastic pallets should be clean and free of damage. Chipping of wood can lead to contamination of food and measures should be in place to ensure that equipment are maintained well.

\section{Rationale:}

The limited acceptance of wood as a food contact surface is determined by the nature of the food and the type of wood used. Moist foods may cause the wood surface to deteriorate and the surface may become difficult to clean. In addition, wood that is treated with certain preservatives may lead to illness due to the migration of the preservative chemicals in the wood, into the food.

\subsection{Use of Linens and Other Accessories}

Linens such as wiping towels, table cloths, aprons, clothing, uniforms, etc. may be used in food premises. They should be of light-colour, kept clean and in a hygienic condition.

a. Cleanliness

i clean linens should be free from food residues or other soiling matters. They should be washed if they become wet, sticky or soiled; and

ii linens should be cleaned and disinfected as often as necessary. This may be achieved by a hot wash in a commercial washing machine, by immersing in boiling water for not less than one minute or by using a disinfection agent approved by the Food Control Department.

b. Sole Use of Linens

Linens should be used for one single purpose only. For example, wiping towels used for wiping food spills on table surfaces should not be used for any other purpose such as for polishing dried utensils or wiping raw animal foods.

c. Wiping Towels

Use of cloths for drying of food contact surfaces of equipment is not recommended as the cloth is likely to contain bacteria or contaminants that would be transmitted to the equipment during the drying process. Food contact surfaces should be air dried. Dry clothes or disposable paper towels may be used for polishing dried utensils.

d. Protective clothing, including aprons and uniforms

Aprons, clothing and uniforms should be clean and fit to wear. Buttons should preferably be avoided for those who directly handle food to prevent them from falling into food. Protective clothing should be washed at least once a day, or when it becomes soiled or sticky.

e. Table Cloths

Table cloths should be cleaned after each use as they have been in contact with food remnants and debris. 


\section{f. Menu cards}

Menu cards that come in contact with hands, food remnants and debris should be kept clean at all times.

\section{g. Storage of Soiled Linens}

Soiled linens should be kept in suitable receptacles or laundry bags away from food preparation areas to prevent contamination of food, food contact surfaces, food equipment and utensils.

\section{Rationale:}

Linens are likely to contain foreign substances such as hair, dirt and micro-organisms, all of which would contaminate food and equipment. It should not be allowed to come into contact with food or food equipment / utensils unless thoroughly cleaned and disinfected. Napkins and menu cards for customers may help transmit diseases from person to person, unless adequately cleaned and disinfected after each use. 


\section{Annex}

\section{A. Documents and Records for Food Establishments}

The following documents shall be maintained in all food establishments if relevant to their activity. Records should be kept in a special folder and should be made available to the Food Inspection Officer or any Authorised Official from the Food Control Department upon request.

1. Food Inspection book

2. PIC Handbook

3. Copy of the trade licence

4. Layout of the food establishment that has been approved by the Food Control Department

5. Occupational health cards for the food handlers issued by Dubai Municipality.

6. Certification of successful completion of food safety training

7. Certificate of Person in Charge

8. Original contract with a pest control company and record of visits

9. Grease trap cleaning contract

10. Cleaning Programme

11. Supplier/Source details

12. Time and temperature records for:

i receiving and storage of high risk foods;

ii verification of cooking temperature;

iii verification of hot and cold holding temperature;

iv time control records when 'time' is used as a control.

13. Appropriate internal or external calibration records for those equipment or measuring devices in which the accuracy of the measurements could affect food safety

14. Sick food handler reports and employee sick leave records

15. Copies of food transportation vehicle permits when necessary

16. A copy of water tank cleaning contract

17. Complaint record

18. Recall form

\section{B. External Links}

1. Dubai Municipality www.dm.gov.ae

2. Emirates Authority for Standardization and Metrology (ESMA) www.esma.ae

3. Dubai Accreditation Department (DAC) www.dac.gov.ae 